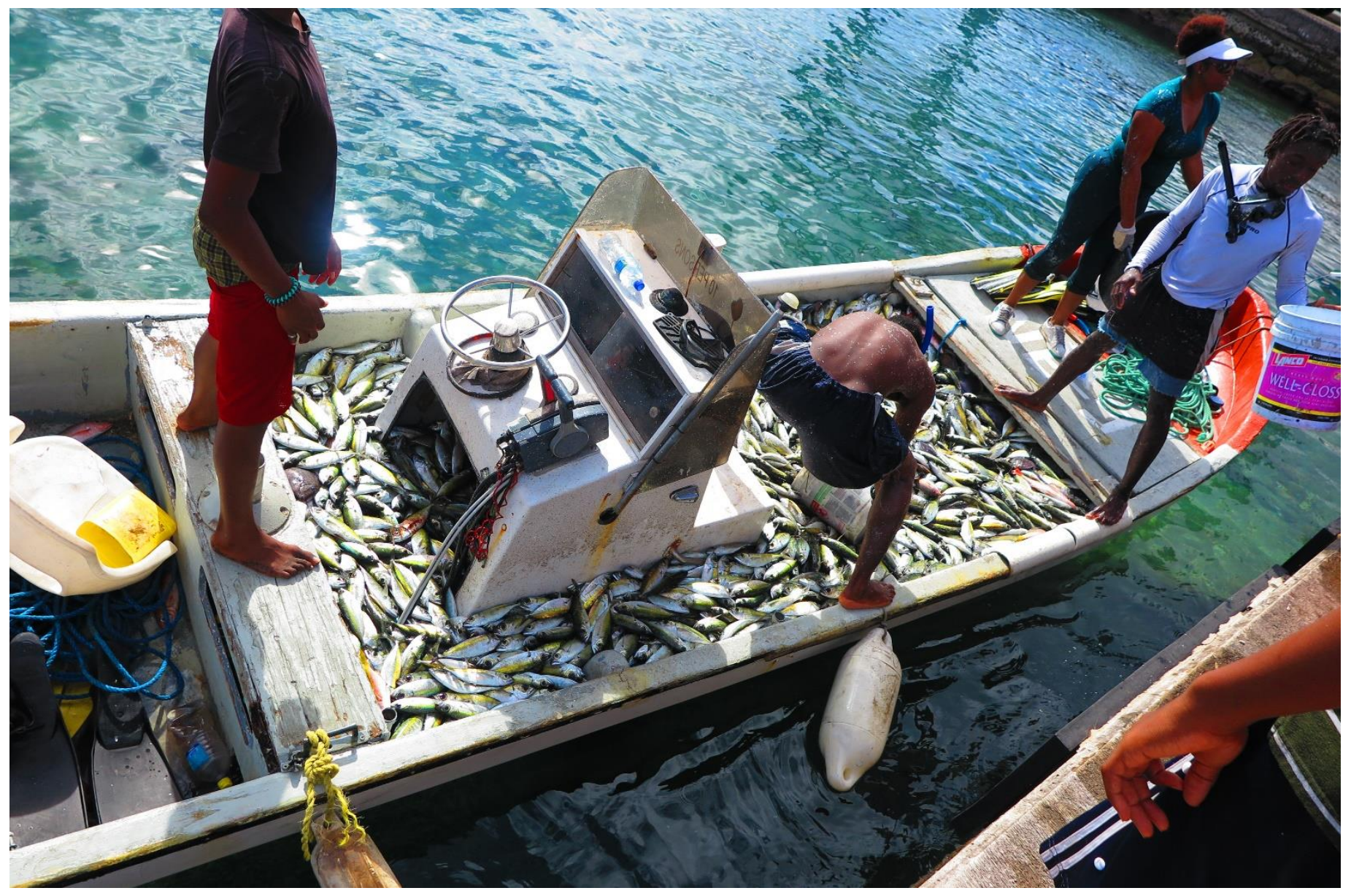

\title{
Update on the 2012-2018 trends in the
}

St Eustatius fisheries 


\title{
Update on the 2012-2018 trends in the St Eustatius fisheries
}

Author(s): $\quad$ Thomas Brunel ${ }^{1}$, Dolfi Debrot ${ }^{1}$, Kimani Kitson-Walters ${ }^{2}$

\author{
1: Wageningen Marine Research \\ 2 : Caribbean Netherlands Science Institute
}

This research project was carried out by Wageningen Marine Research at the request of and with funding from the Ministry of Agriculture, Nature and Food Quality for the purposes of Policy Support Research Theme 'Vis en Visserij Caribisch Nederland' (project no. BO-43-021.04-006).

Wageningen Marine Research

IJmuiden March, 2020

CONFIDENTIAL no

Wageningen Marine Research report C031/20 
Keywords: fisheries trends, St. Eustatius, Caribbean Netherlands, port sampling.

Client: $\quad$ Ministry of Agriculture, Nature and Fisheries (LNV)

Attn.: Drs. Hayo Haanstra

Postbus 20401

2500 EK Den Haag

BO-43-021.04-006

This report can be downloaded for free from https://doi.org/10.18174/519381

Wageningen Marine Research provides no printed copies of reports

Wageningen Marine Research is ISO 9001:2015 certified.

Photo cover: Kimani Kitson-Walters

(C) Wageningen Marine Research

Wageningen Marine Research, an instituteWageningen Marine Research accepts no liability for consequential damage, nor within the legal entity Stichting Wageningenfor damage resulting from applications of the results of work or other data Research (a foundation under Dutch privateobtained from Wageningen Marine Research. Client indemnifies Wageningen law) represented by Dr. M.C.Th. Scholten,Marine Research from claims of third parties in connection with this application. Managing Director All rights reserved. No part of this publication may be reproduced and / or

KvK nr. 09098104, published, photocopied or used in any other way without the written permission WMR BTW nr. NL 8113.83.696.B16.

Code BIC/SWIFT address: RABONL2U

IBAN code: NL 73 RABO 0373599285 


\section{Contents}

Update on the 2012-2018 trends in the St Eustatius fisheries

Summary

$\begin{array}{llr}1 & \text { Introduction } & 5\end{array}$

2 Methods $\quad 6$

2.1 Data collection $\quad 6$

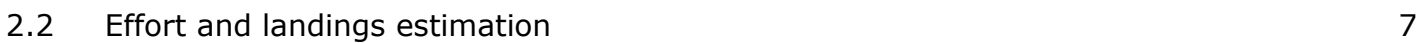

2.3 Landings species and length composition 9

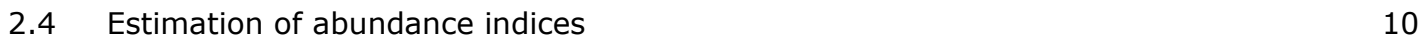

$\begin{array}{llr}3 & \text { Results } & 11\end{array}$

$3.1 \quad$ Fishing activity and landings 11

$\begin{array}{lll}3.1 .1 & \text { Effort } & 11\end{array}$

$\begin{array}{lll}3.1 .2 & \text { Fishing methods } & 11\end{array}$

3.1.3 Landings per species category $\quad 12$

$\begin{array}{lll}3.2 & \text { Trap fishery } & 13\end{array}$

$\begin{array}{lll}3.2 .1 & \text { Lobster landings } & 13\end{array}$

3.2.2 Mixed fish landings $\quad 16$

$\begin{array}{llr}3.3 & \text { Diving } & 18\end{array}$

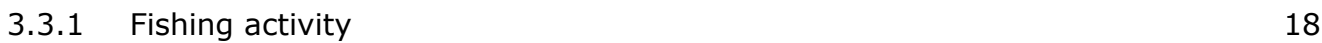

$\begin{array}{lll}\text { 3.3.2 } & \text { Mixed Lobster / reef fish fishery } & 18\end{array}$

$\begin{array}{ll}3.3 .3 & \text { Conch fishery }\end{array}$

$\begin{array}{ll}3.4 & \text { Handlines } \\ & 22\end{array}$

3.4.1 Species composition of the landings $\quad 22$

3.4.2 CPUE standardisation using a GLM model $\quad 22$

$\begin{array}{lll}3.5 & \text { Trolling } & 24\end{array}$

3.5.1 Species composition of the landings $\quad 24$

3.5.2 CPUE standardisation using a GLM model $\quad 24$

4 Discussion $\quad 26$

$\begin{array}{lr}\text { Quality Assurance } & 29\end{array}$

$\begin{array}{lr}\text { References } & 30\end{array}$

$\begin{array}{lr}\text { Justification } & 31\end{array}$

Annex 1 : Logbook forms used in data collection $\quad 32$

Annex 2 : monthly estimates of effort, catch rates and landings per métier per species category. 


\section{Summary}

This report presents an overview of the trends in St Eustatius fisheries based on the fisheries data collected on the island during 2012-2018. The fishery on St Eustatius remains mostly conducted by small open boasts with outboard engines. The number of fishing trips carried out by the fleet increased over 2014 peaking in 2015 with roughly 100 trips per months, and subsequently decreased in the following years to an average of 25 trips per month in 2018.

The main activity is a lobster fishery using traps, also catching a mix of reef fish. This fishery is responsible for nearly $70 \%$ of the lobster landings on St Eustatius. The trend in the annual landings in this fishery broadly follows the trends in the fishing effort, with landings reaching 30 tonnes in 2015 and decreasing to 9 tonnes in 2018. Landings of lobsters from the trap fishery show a strong seasonality with higher landings from September to March, and low landings during June-July. The abundance index (derived by modelling the landings per trip) indicates an overall increase in abundance from 2012 to 2017, and an apparent decrease in lobster abundance in 2018. The average carapace length (CL) shows interannual variations without any specific trend, but is on average $95 \mathrm{~mm}$ for females and 102.5 for males. This means that an average of $41 \%$ of the lobsters are landed below the legal size limit (95 $\mathrm{mm})$. This problem is especially acute for females of which $56 \%$ of the landings are of sublegal size.

The species composition of the bycatch of reef fish in the lobster traps is very diverse, and is dominated by Acanthuridae (Blue Tang, Doctorfish, Surgeonfish), Ostraciidae (Honeycomb and Scrawled Cowfish) and Serranidae (Coney and Red Hind). The trends in the reef fish bycatch in the lobster traps also followed the trend in effort, with values ranging from 1.7 to 9.9 tonnes caught per year. The biomass index calculated from the catch per trip suggests a decrease in fish abundance between 2014 and 2016 and a small increase thereafter. Length frequency data for the main fish species caught in the lobster traps do not show any notable changes over the period studied.

The second most important fishing activities after trap fishing are scuba diving and free diving. Both activities catch lobster and fish, but while lobster and fish (mainly Coney, Red hind and Lionfish) are in equal proportion in the landings from scuba diving, landings from free diving are largely dominated by lobsters. The lobster abundance index calculated from the catches per trip in free and scuba diving shows an increase from 2012 to 2016, and a sharp decrease thereafter. This is overall the same pattern as seen in trap-caught lobsters. The difference with the trend in the abundance index calculated based on trap data might be explained by spatial and depth differences in the distribution of the fishing effort between those fisheries. Scuba divers also conduct a fishery targeted on conch, representing roughly $40 \%$ of the trips. Estimates of the annual conch landings are very variable, and likely to be fairly uncertain due to the lack of information from logbooks in some years. The mean length of the conch landed appears to be stable over time, at $24.5 \mathrm{~cm}$ and $23.7 \mathrm{~cm}$ for females and males respectively.

Next to the traps and diving fisheries, different line fisheries are conducted on St Eustatius. A handline fishery on reef fish produced landings between 0.3 and 4.3 tonnes per year in the period 2014-2017, but with much lower estimates in 2018, mainly due to a drop in effort for this year. Large pelagic fish are also caught by trolling, with landings varying between 0.6 and 2.5 tonnes per year.

Our main recommendations in terms of both management and research and monitoring are as follows:

- Improve control of and compliance with lobster size-limit regulations.

- Develop a FAD fishery management plan as part of a St. Eustatius fisheries development plan.

- Improve port sampling monitoring and subsampling intensity to cover at least one third of the trips dedicated to each fishing metiér.

- Conduct a closer study on both the Coney and the Red Hind. Do this by combining more intensive port sampling and fisheries independent studies on the distribution and abundance of these species around St. Eustatius. 


\section{Introduction}

A fleet of about 20 fishing boats operates on St Eustatius (de Graaf et al. 2015), however, the number of boats that actively fish full-time is $\leq 5$. All other vessels do so on a part-time basis. All boats are open boats ranging between 5-10 m in length and powered by single or twin outboard engines. The most commonly used fishing gear is the Antillean style arrowhead trap, usually built from chicken wire around a wooden or steel frame. This fishery targets spiny lobster, and has a bycatch of mixed reef fish. In addition to trapping, both mixed reef fish (spear gun) and lobster (snare) are caught using the different methods of either free diving or scuba diving. The fleet also has different line fisheries, among which trolling for large pelagic fish is the main activity.

In 2012, WMR (then named IMARES) was commissioned by the Dutch Ministry of Economic Affairs to start working with local organizations on baseline marine resource studies and the development and implementation of robust, efficient and (internationally) standardized monitoring programs of coral reef health indicators in the Caribbean Netherlands. As part of this activity, a fisheries research programme was initiated on St Eustatius, and has since then been continued. Fisheries data collection is currently carried out on both Saba and Statia by Data Management Officers funded by the Dutch government. A previous WMR report (de Graaf et al. 2015) made an assessment of the status of the coral reefs in St Eustatius, based on a number of health indicators (Fish biomass, Coral and algae cover, Coral recruitment and health, Water quality, Status of sharks, Status and trends in the fishery). As part of that assessment, a first analysis of the fisheries data collected on St Eustatius was presented. The present report gives an update of these analyses on the St Eustatius fisheries, based on data collected between 2012 and 2018. In addition to estimates of landings for the main species groups and effort for the main fishing gears, abundance indices are also calculated based on the average landings per trip, to indicate the relative developments in abundance of the main species groups over the last 7 years. 


\section{Methods}

\section{$2.1 \quad$ Data collection}

A sample-based fishery survey (Stamatopoulos, 2002) was implemented in 2012 to collect basic data on catch, effort, species composition and length frequency of the fishery on St Eustatius. Rather than directly counting all catches, the total catch for each boat for each of the fishing methods was estimated by using data on the number of boats, the activity level of the boats and the average catches per boat per day.

Schematic representation of the survey design

The generic formula for estimating catch is:

Catch $=$ CPUE $\times[B A C \times F \times A]$

Where:

CPUE is estimated from a Landings Survey

BAC is estimated from a Boat Activity Survey

$F$ is provided by a Frame Survey

A is determined by an Active Days Survey

Frame Survey: A frame survey is a census-based approach to collate a list of homeports and boat/gear categories which is used as the basis for the Active Days, Boat Activity and Landings surveys. This entails generating a list of all fishing vessels on island and associated gear types used by that vessel The frame surveys is conducted at the start of each year and is updated monthly throughout the year.

Active Days Survey: Active Day Surveys are conducted at the end of each month to determine the number of active fishing days for each stratum in the survey design (e.g. home port, boat).

Boat Activity Survey: Boat Activity Surveys are conducted at homeports separately for each boat to determine how many boats are active on a given day. These surveys are conducted 7 days per week by contacting each vessel to ascertain their activity on each day based on the results of the Active Days Survey. Note that these surveys are not always successful and is dependent on the willingness of the vessel owner to participate.

Landings Survey: Landings Surveys consist of collecting fishing logbooks, filled by part of the fleet, which provide data per trip on landings (in number or weight depending on the species categories), gear types used, number of each gear deployed, and other operational information, and, for a sub-sample of the trips, conducting biological sampling to estimate the species composition and the length frequency of the fish landed (See annex 1 for Logbook forms used in data collection). The gear types used by fishing vessels are fish/lobster traps, scuba diving, free diving, handline, trolling, dropline and longline. The logbooks are recovered at the same time as the Boat Activity Surveys and is also affected by the willingness of the vessel owner to participate. 


\subsection{Effort and landings estimation}

\section{Estimates of Number of trips:}

The number of trips carried out per month was calculated from the activity survey only. In order to take account of the fact that there was not a $100 \%$ coverage of the vessel activity (i.e. several days in the month with no observation on vessel activity), a first raising of the number of trips was operated as follows:

\section{raised number of trips $=$ number of trips observed / survey coverage rate}

The survey coverage rate is typically around $40 \%$ for the period before 2018 , and closer to $100 \%$ since 2018 (Figure 1).

Some inconsistencies between logbooks and activity survey were noticed, with occasionally boats having more trips registered in certain months in the logbooks database than the number estimated based on activity. This can be explained based on the assumption that the number of trips is evenly spread through the month, and is the same as for the days covered by the logbooks. Of course, this is not necessarily true and means that when raising the activity to cover the whole month, differences can be expected between "estimated" and "observed". In cases where more trips were actually registered in the logbooks than estimated based on the activity survey, the number of trips in the logbook database was used instead of the raised number of trips from the activity survey.

From May 2017 to April 2018, the activity survey was discontinued, and therefore, there was no direct observation of the number of trips conducted. For these months, the number of fishing trips was inferred from the number of fishing trips registered in the logbooks database. The average ratio of this number of trips from the logbooks and the estimated monthly number of trips per boat was calculated for each fishing method, and used to raise the number of trips based on the logbooks to the total monthly number of trips for this period without activity survey.

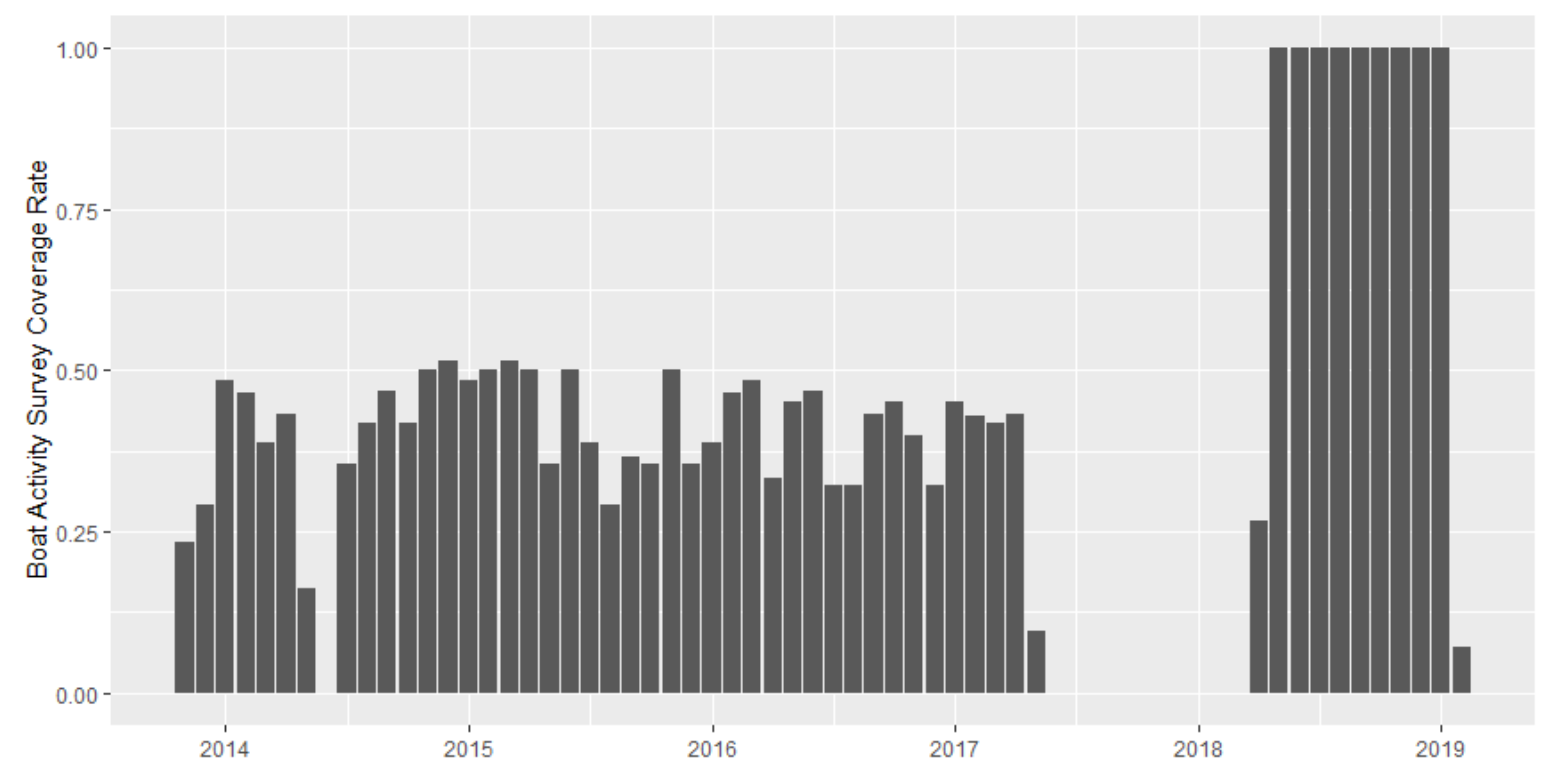

Figure 1. Rate of coverage of the boat activity survey (fraction of the days in a month when boat activity was recorded)

\section{Number of trips per fishing method:}

For the part of the fleet delivering logbooks, it was possible to split the effort between fishing methods (trapping, free diving, scuba diving, handlining, trolling). First, at the boat/month level, the proportion of each fishing method is calculated from the logbook and multiplied by the raised number of monthly trips (from the activity) for the corresponding boat to get an estimate of the number of trips per fishing 
method per boat. Summing over the boats having delivered logbooks, gives an estimate of the effort per fishing method for the part of the fleet delivering logbooks.

By comparing the active boats each month (activity) with the boats delivering logbooks, the \% of logbook coverage can be estimated (Figure 2), and used as a raising factor to estimate to effort per fishing method at the scale of the entire fleet. Again, for the period with no activity survey, the mean $\%$ of logbook coverage was used (grey bars on Figure 2).

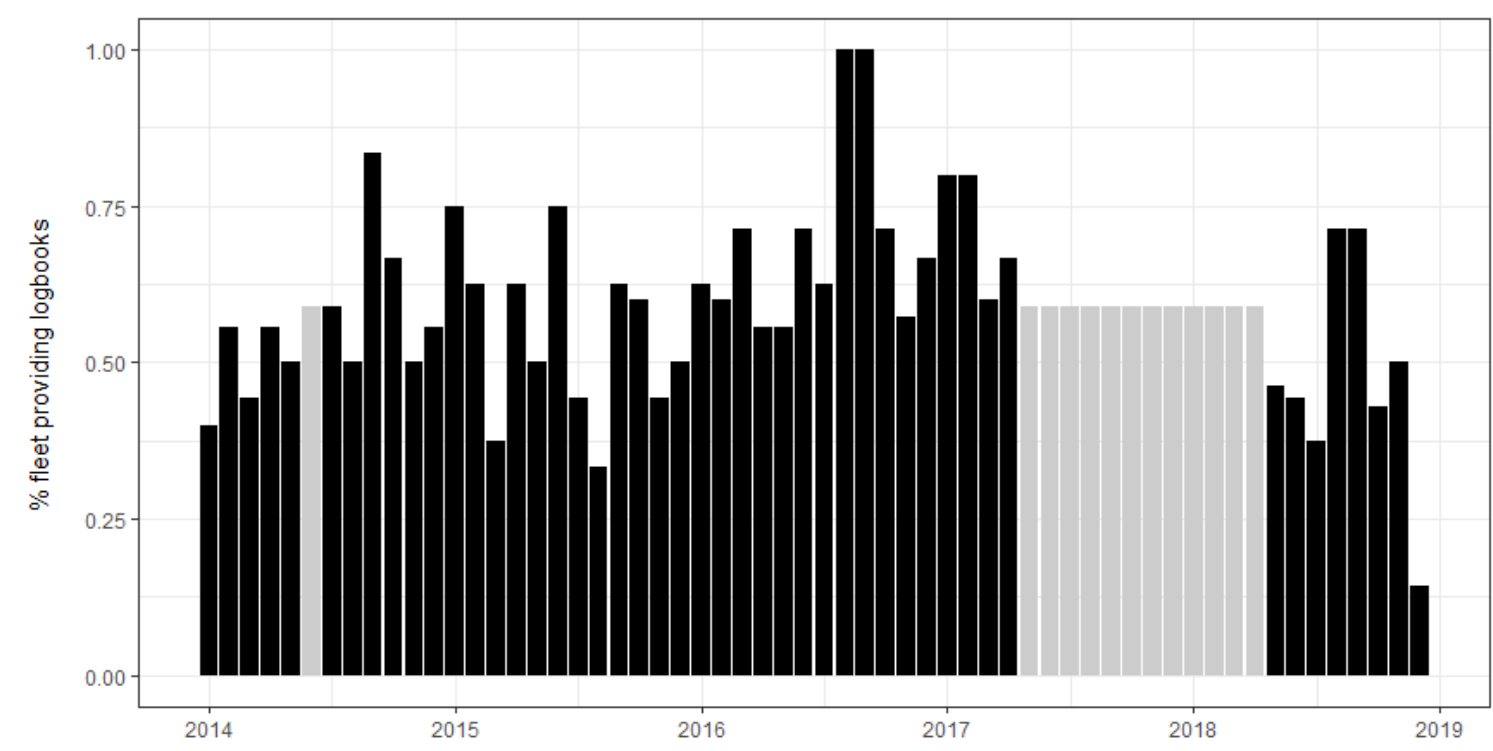

Figure 2. Proportion of the active boats providing logbooks each month (in grey: for month without activity log, the mean value is assumed)

\section{Annual landings per species category}

Landings per trip are reported by species categories. The categories considered in this report are the lobster, reef fish, pelagic fish and conch.

Since not all vessels deliver logbooks, the calculation of the landings (i.e. multiply CPUE by effort) was not done on a per vessel basis, but using average CPUE across those boats that delivered logbooks in a given month and total effort per fishing method calculated as described above.

Conch is a relatively limited fisheries, and after consultation of local experts, it appeared that all the vessels involved in this fisheries (between 1 and 5 depending on the years) were actually delivering logbook. For this reason, the total effort and catches for the conch fishery were based only on the data of those boats providing log books, and no raising to the total fleet was done (we thank Dr. Erik Boman for his critical review regarding this matter). Figure 3 summarizes the successive steps and raising procedures to estimate monthly landings and effort. 


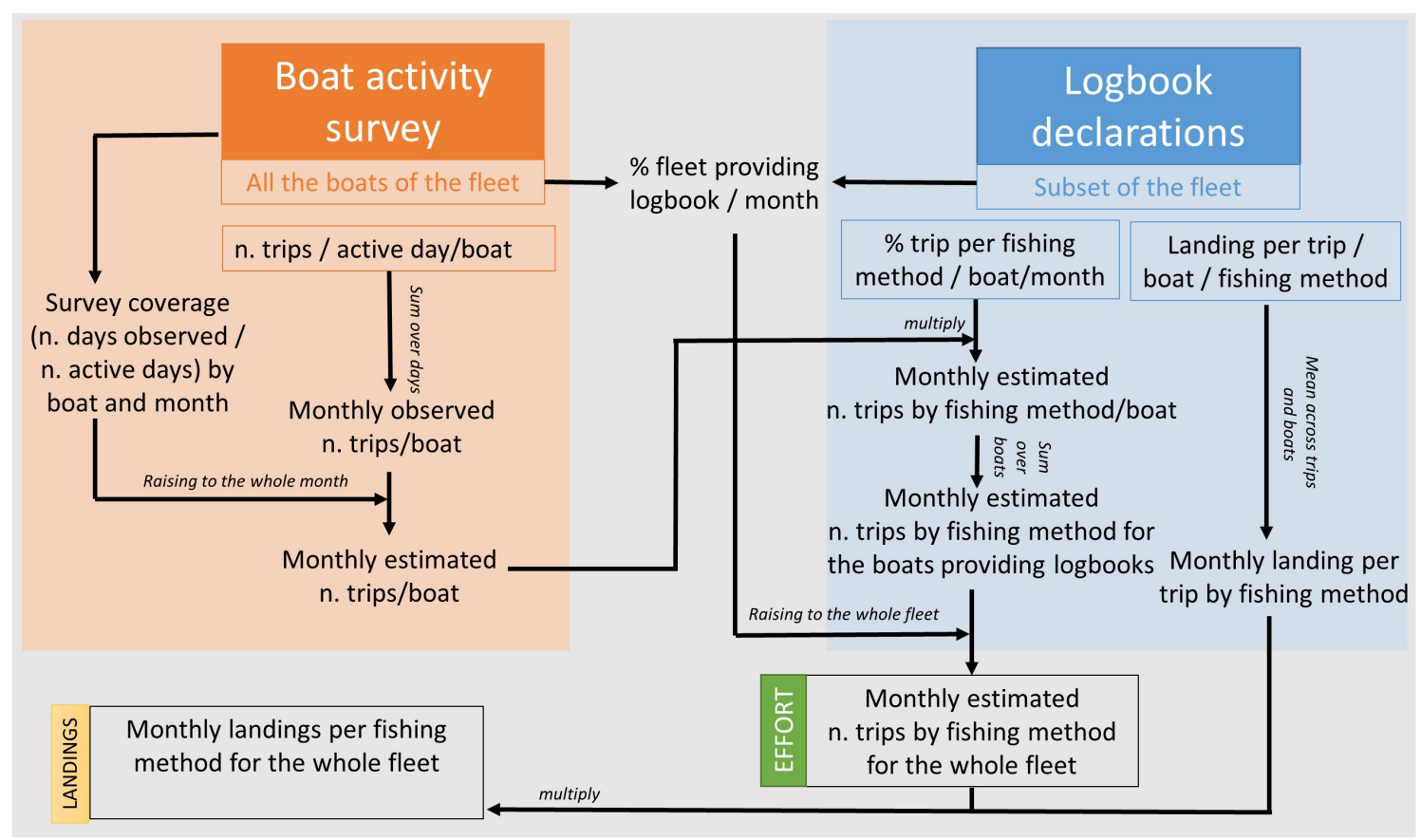

Figure 3. Estimation method for the monthly landings per species category and "métier" (fishing method) and monthly effort by métier.

\subsection{Landings species and length composition}

For a subset of the trips, sampling of the landings was conducted both for species and length composition. For some fishing methods (free diving and handlines), the number of samples for species composition is very low. For the length measurements, there are only few samples of fish available for the trolling and the free diving activities, and only few samples of lobsters from the scuba diving fishery.

Table 1. Number of samples available for the period 2011-2018 per fishing method for the species and length composition of the landings. FD : free diving, HL : handline, PT : lobster traps, SD : scuba diving, TR : trolling

\begin{tabular}{lccccc}
\hline species composition samples & \multicolumn{7}{c}{} \\
\hline & $\mathrm{FD}$ & $\mathrm{HL}$ & $\mathrm{PT}$ & $\mathrm{SD}$ & $\mathrm{TR}$ \\
trips sampled & 3 & 4 & 66 & 36 & 102 \\
total number of fish & 5 & 74 & 2566 & 656 & 726 \\
& & & & & \\
\hline Length measurements & & & & & \\
\hline & $\mathrm{FD}$ & $\mathrm{HL}$ & $\mathrm{PT}$ & $\mathrm{SD}$ & $\mathrm{TR}$ \\
number of fish & 13 & 427 & 9213 & 586 & 40 \\
number of lobsters & & & 2735 & 97 & \\
number of conchs & & & & 2331 & \\
\hline
\end{tabular}

\section{Lobster vs. fish}

Some methods target both lobster and a mix of reef fish. The proportion of these two species categories was estimated based on the landings per trip as declared in the logbooks. Lobster landings are declared in numbers while fish landings are declared in weight. Available lobster length measurements were used to compute the average size of the lobsters in the landings, which was subsequently converted to average individual lobster weight. Landings per trips in number were then converted into landings in weight using the average lobster weight. 


\section{Proportion of fish species}

For a subset of the trips with logbook data (216 trips in total, see table 1 for the distribution of samples across fishing methods), port sampling was conducted to estimate the species composition of the landings. This data was used to analyze the yearly species composition of the landings for the different fishing methods.

\subsection{Estimation of abundance indices}

In order to get annual abundance indices for the main species groups, landings and effort data from the logbooks were analysed for each of the main species groups for each of the fishing methods. Part of the variations in the annual mean landings per trips reflects other factors than changes in abundance, such as changes in overall effort, monthly or spatial repartition of the effort or even different contributions of different vessels to the annual effort. In order to standardise the landings per trip and extract an annual abundance index, the landings per trip where modelled for each of the main species groups and for each of the fishing methods using a GLM with a negative binomial distribution. The formulation of the full model is as follows:

$\begin{array}{ll}\log (\text { landings per trip) } \quad=\quad & \text { intercept } \\ & + \text { Year effect } \\ & + \text { Month effect } \\ & + \text { Boat effect } \\ & + \text { soaking time } \\ & +\log \text { (trap number) }\end{array}$

Model selection was done by fitting the full model, fitting sub-models dropping each of the explanatory variables one by one, and then conducting a likelihood ratio test to assess whether each explanatory variables from the full model is significant. In case not all model terms are significant, the explanatory variables with the highest $\mathrm{p}$-value is then remove from the model. this procedure is repeated until all remaining explanatory variables have a significant effect.

The model formulation above corresponds to the model applied to the lobster landings, in which the response variable is the number of lobsters caught in one trip, and the explanatory variables representing the fishing effort deployed during the trip are soaking time (number of days of immersion of the traps that were lifted during the trip) and number of traps. For other species, different units may be use for the landings (e.g. kg), and for different fishing methods, different variables may represent fishing effort (e.g. number of divers, number of fishing lines ...). In cases where the response variable was in kilograms, a GLM with a log Gaussian distribution was used.

In this formulation of the model, one parameter is estimated for the intercept and for each of the levels of the different effects (year, month, boat and area). One parameter is also estimated for the linear regression of log landings (number) against the log of the fishing effort (in trap numbers, hours of diving). The chosen model formulation implies a power function between the landings and the effort, which is the formulation typically used for ad hoc standardisation of catch rates in trap fisheries. The parameter estimated for this variable corresponds to the exponent of the power function, which, in case saturation indeed occur, is expected to be smaller than 1 .

The year effects estimated by this method correspond to the variations in the landings per trip which are explained by the year, when all other sources of variation have been taken into account (including the changes in effort). These year effects can therefore be interpreted as abundance indices. 


\section{$3 \quad$ Results}

\subsection{Fishing activity and landings}

\subsubsection{Effort}

The monthly effort (number of trips) of the fleet was estimated based on the data from the boat activity survey (and when it was not carried out, extrapolated from the logbook data). The monthly estimated number of trips was very variable with no unidirectional trend over the period 2014-2018. Between the last months of 2014 and mid-2016 the number of trips was constantly higher than 50 per month (figure 4), and frequently over 100 trips per month. For the period before October 2014 and after June 2016, the monthly effort was usually around 25 trips, with even lower values since February 2017. The proportion of the trips for which no logbook data was available (white part of the bars on Figure 4) is variable, with months of good logbook coverage (e.g. August/September 2016) to months with a low coverage (August 2014, December 2018).

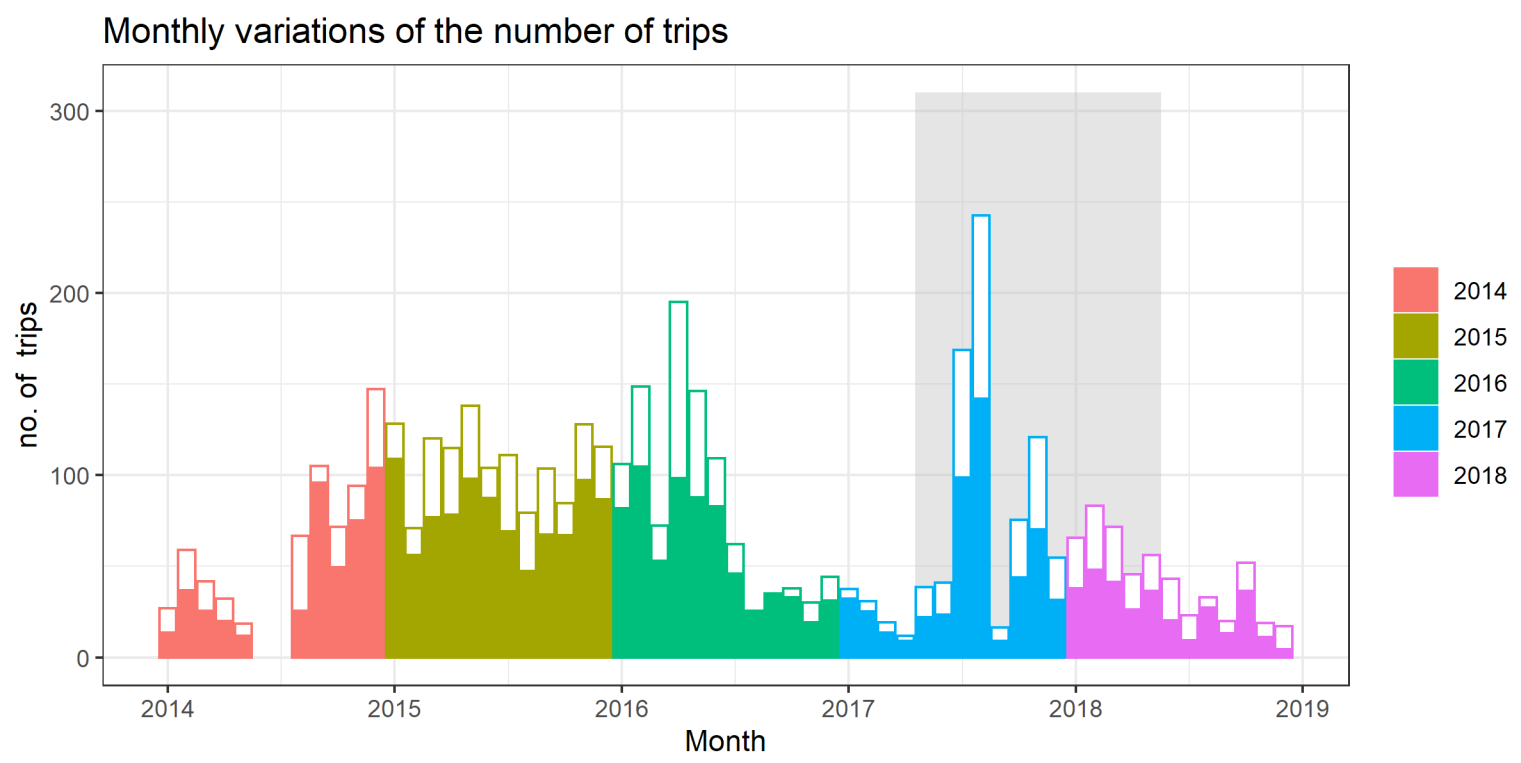

Figure 4. Estimated number of trips per month. The white part of the bars represents the number of trips registered in the activity survey corresponding to boats not providing any logbook data. Note that there is no data available for June and July 2014, nor for the period May 2017 to May 2018 (grey area). For these periods, the number of trips is inferred from the logbook information only (no activity survey, see section 2.2).

\subsubsection{Fishing methods}

Based on the logbooks that were available, it was possible to estimate the relative importance of the different métiers in the activity of the fleet. The importance of each métier is quite variable from one month to the next, and there is no clear temporal trend in the data (Figure 5). The lobster traps appear to be consistently the most used gear, representing overall $28 \%$ of the trips. Free diving and handlines are also two important fishing practices (23\% each). Other fishing practices represent smaller percentages of the activity ( $14 \%$ and $15 \%$ for scuba diving and trolling respectively). 


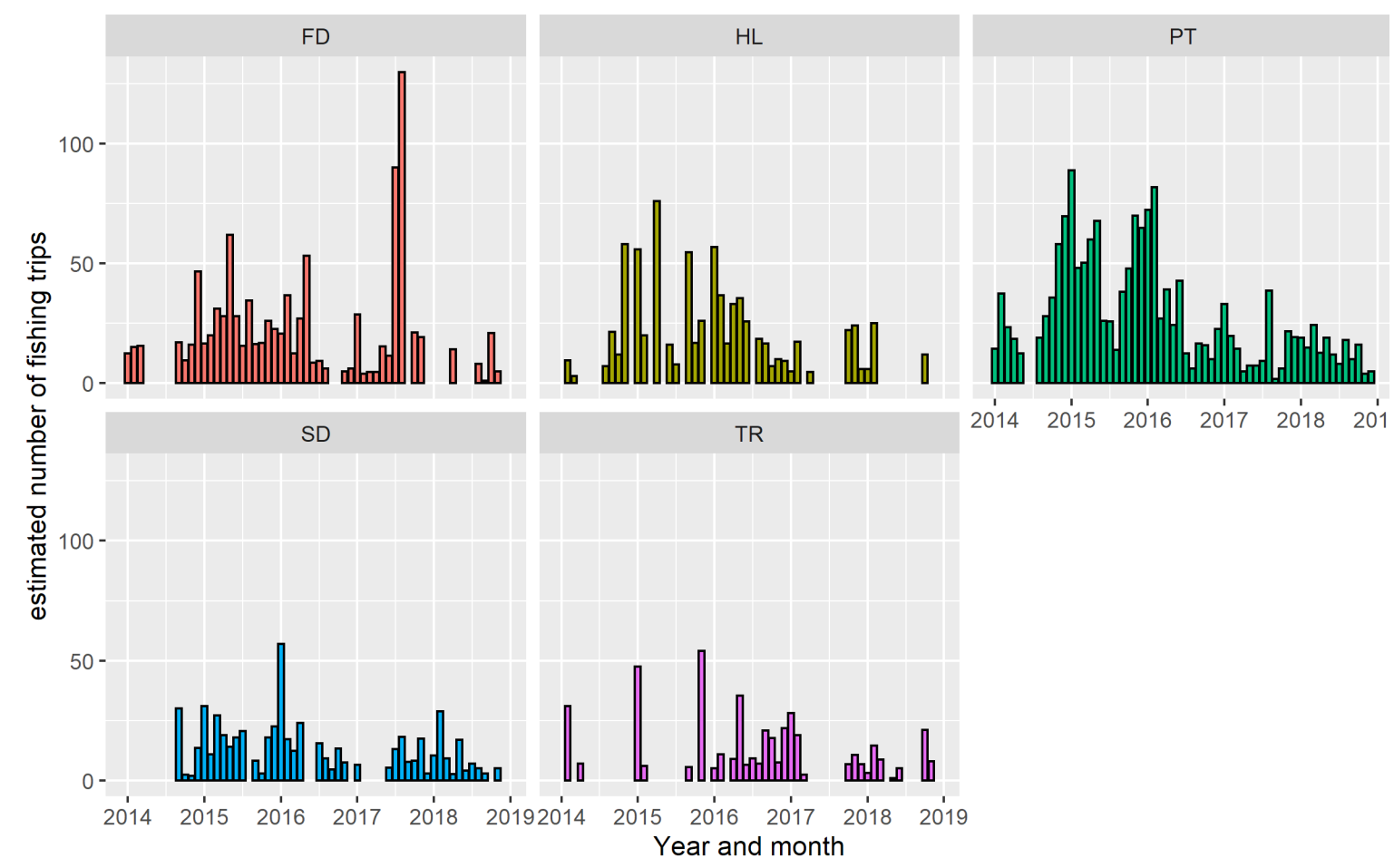

Figure 5. Monthly proportion of the fishing trips for each métier. FD: free diving, HL: handline, PT: lobster traps, SD: scuba diving, TR: trolling.

\subsubsection{Landings per species category}

The main species of interest is the Caribbean Spiny Lobster, Panulirus argus, which is caught mainly using lobster traps (68\%) and in free and scuba diving (21 and $11 \%$ respectively). Monthly estimates of the number of trips, catch rates and landings of lobster per métier are given in annex 2 , and the yearly total landing values are given in table 2. The estimated annual landings of lobster were the highest in 2015 (48.5 tonnes) and were in comparison low in 2018 (around 12 tonnes). This trend is quite similar to the variations observed in the number of trips (which were the highest in 2015) and shows no correlation with the changes in the average landings per trip, which were not higher in 2015 than in other years (annex 2).

Similar to the lobster, most of the reef fish landings were taken by the trap fishery (44\%), with also a significant contribution from free diving (24\%) and handlines $(26 \%)$ and a smaller share from scuba diving (7\%). Annual landings were higher during the period 2014-2016 (between 10 and 17 tonnes annually) and decreased to lower levels (5 to 7 tonnes) between 2017 and 2018. Again, this decrease seems to be more related to the changes in fishing effort than to any change in the catch rates of the different métiers (annex 2).

Landings of pelagic fish caught by trolling are on a lower scale, ranging annually between 0.6 tonnes in 2014 to 2.5 tonnes in 2016. For this category as well, there are no marked differences between years in the catch rates (annex 2), and the differences in annual landings values seem to be more related to the variations in the number of trips carried out.

Finally, estimates of landings of conch in the scuba diving fishery were highly variable, ranging from 1 317 individuals in 2014 to 6588 in 2015 . The particularly low value in 2014 is explained by the fact that landings of conch were only registered in the logbook data for 4 months of the year, and it is unknown whether it was because there were no trips targeting conch during the rest of the year, or because no logbooks from conch trips were available.

For all species categories, the estimated landings for 2017 and 2018 were based on monthly effort inferred from logbook data but only for the months without activity survey. This means that the estimates for these two years have additional uncertainty compared to other years, due to the crude assumption made that the number of trips for which logbooks were provided is proportional to the total number of trips carried out. 
Table 2. Estimation of the annual landings per métier in tonnes per species category (PT = lobster traps, $\mathrm{FD}=$ free diving, $\mathrm{SD}=$ scuba diving, $\mathrm{HL}=$ handlines, $\mathrm{TR}=$ trolling)

\begin{tabular}{|rccccccccccccc|}
\hline \multicolumn{4}{l}{ Lobster } & \multicolumn{3}{c}{ reef fish } & \multicolumn{3}{c}{ pelagic fish } & All gears & conch \\
\hline \multicolumn{3}{|c}{ (tonnes) } & & \multicolumn{3}{c}{ (tonnes) } & & & (tonnes) & (tonnes) & (number) \\
\hline Year & PT & FD & SD & total & FD & HL & PT & SD & total & TR & total & SD \\
\hline 2014 & 26.4 & 2.8 & 1.0 & 30.2 & 1.0 & 4.3 & 6.3 & 0.2 & 11.8 & 0.6 & 42.6 & 1317 \\
2015 & 30.8 & 12.5 & 5.3 & 48.5 & 5.0 & 1.7 & 9.9 & 0.7 & 17.2 & 0.7 & 66.4 & 6588 \\
2016 & 13.9 & 4.3 & 3.1 & 21.2 & 2.4 & 4.2 & 3.0 & 0.5 & 10.2 & 2.5 & 33.9 & 5135 \\
2017 & 9.0 & 6.1 & 1.9 & 16.9 & 1.7 & 2.4 & 1.7 & 0.9 & 6.6 & 0.9 & 24.4 & 4528 \\
2018 & 8.8 & 1.8 & 1.4 & 12.0 & 1.6 & 0.3 & 2.6 & 0.5 & 4.9 & 1.8 & 18.7 & 2607 \\
\hline
\end{tabular}

\subsection{Trap fishery}

\subsubsection{Lobster landings}

\section{Proportion of lobster in the landings by weight}

Reef fish and lobsters each represent roughly half of the landings by weight in the trap fishery (Figure 6). These proportions are relatively stable across the years, except for 2014 and 2016 when lobster landings corresponded only to $25 \%$ of the landings.

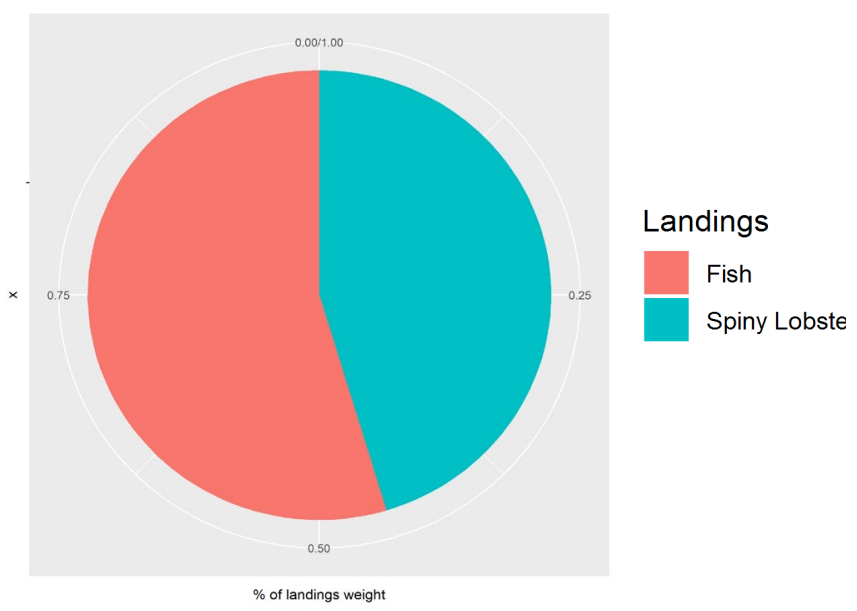

Figure 6. Average proportion of lobster and reef fish in the landings in weight of the trap fishery over the period 2012-2018.

\section{CPUE standardisation using a GLM model}

The unstandardized lobster CPUE (lobster landings per trip) of the trap fishery are shown in the annex 2. There is a clear seasonality, with higher landings per trip for the winter months than for the summer months. The GLM model was fitted to estimate the influence of different factors on the CPUE, and extract an abundance index (year effect). This analysis was based on a subset of five boats selected on the basis of importance of the PT gear in their activity, and which were consistently active throughout the period studied.

All the factors included in the model were found to have a significant effect (Table 3). The landings per trip were positively related to both the number of traps set during the trip and the soaking time. There were also clear differences in fishing effectiveness between the vessels used for the analyses, with a ratio of around 1:2 between the least and the most effective boats. The estimated month effect (Figure 7) clearly illustrate the seasonality in the catchability of the traps, with lower values from April to August and higher values the rest of the year. Finally, the estimated year effects indicated an increase from low 
abundances in 2012-2013 to intermediate levels in 2014-2016, a further increase to a higher level in 2017, decreasing in 2018 to similar values as in 2014-2016.

Table 3. Significance of each model term tested by removing them stepwise and comparing to the full model (GLM model of lobster catches per trip). AIC stands for Akaike information criterion (the lower the better). * : significant at the $5 \%$ risk level, ** : significant at the $1 \%$ risk level.

\begin{tabular}{|l|l|l|l|l|l|}
\hline Model term removed & $\begin{array}{l}\text { Number of } \\
\text { parameters }\end{array}$ & AIC & $\begin{array}{l}\text { Log- } \\
\text { Likelihood } \\
\text { ratio }\end{array}$ & $\begin{array}{l}\text { P.value } \\
\text { level }\end{array}$ \\
\hline <none> & & 4304.3 & & \\
\hline factor(Year) & 6 & 4348.5 & 56.2 & $2.601 e-10$ & $\star \star$ \\
\hline factor(Month) & 11 & 4419.3 & 137.0 & $<2.2 e-16$ & $\star \star$ \\
\hline factor(Boat_name) & 3 & 4319.8 & 21.5 & $8.172 e-05$ & $\star \star$ \\
\hline Soaking_time_days & 1 & 4337.3 & 35.0 & $3.246 e-09$ & $\star \star$ \\
\hline logTraps & 1 & 4515.2 & 212.8 & $<2.2 e-16$ & $\star \star$ \\
\hline
\end{tabular}
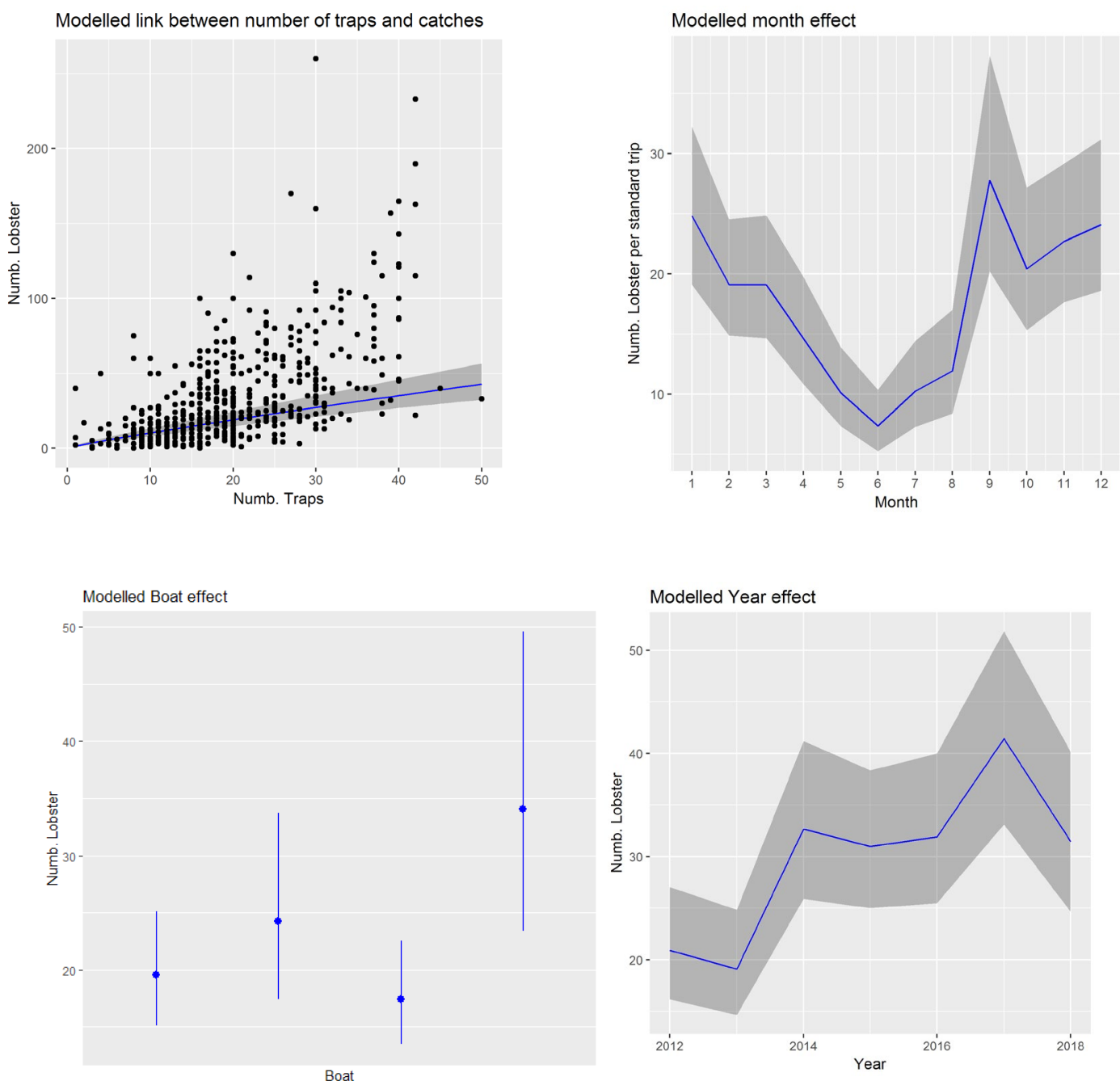

Figure 7. Modelled trap number, month, boat and year effects on the landings of lobsters per trips (in numbers). Blue lines represent the modelled effect (and associated 95\% uncertainty in grey).

\section{Length frequency distribution of the landings}

Length measurements of lobster were available since 2011, almost exclusively from the trap fishery (Table 4). The number of individuals measured varied from more than 1,000 in 2012 to less than 100 in 2016.

The mean length of the females landed is lower than for the males, and for both sexes length displayed similar variations in time, with stable values between 2011 and 2016 (slightly higher in 2013 and slightly lower in 2014, table 4), and higher value for the last two years, especially for the males. The sex ratio 
indicated a predominance of the males in the landings. The proportion of landed individuals below the minimum size ( $95 \mathrm{~mm}$ ) was in the range of $34-48 \%$. Females were consistently caught at a smaller size and a higher percentage below legal size than males ( $54 \%$ below legal size, versus $31 \%$ below legal for males). Sub-legal size capture more greatly affects females than males.

Table 4. Annual mean length, sex ratio and proportion of undersized individuals in the lobster landings (samples mainly from the trap fishery).

\begin{tabular}{|c|c|c|c|c|c|c|c|c|}
\hline \multirow[b]{2}{*}{ Year } & \multicolumn{2}{|c|}{ Mean length (mm) } & \multirow[b]{2}{*}{ Combined } & \multirow{2}{*}{$\begin{array}{l}\text { Sex ratio (males } \\
\text { per female) }\end{array}$} & \multicolumn{3}{|c|}{ Proportion $<95 \mathrm{~mm}$} & \multirow{2}{*}{$\begin{array}{l}\text { Number lobsters } \\
\text { measured }\end{array}$} \\
\hline & Females & Males & & & Females & Males & Combined & \\
\hline 2011 & 95 & 102 & 98 & 1.23 & $55 \%$ & $42 \%$ & $48 \%$ & 165 \\
\hline 2012 & 93 & 103 & 98 & 1.04 & $60 \%$ & $22 \%$ & $41 \%$ & 1055 \\
\hline 2013 & 96 & 103 & 100 & 1.06 & $41 \%$ & $30 \%$ & $36 \%$ & 200 \\
\hline 2014 & 95 & 97 & 96 & 1.44 & $50 \%$ & $40 \%$ & $44 \%$ & 122 \\
\hline 2015 & 95 & 101 & 98 & 1.43 & $55 \%$ & $31 \%$ & $41 \%$ & 216 \\
\hline 2016 & 91 & 101 & 97 & 1.87 & $83 \%$ & $30 \%$ & $48 \%$ & 66 \\
\hline 2017 & 97 & 107 & 102 & 1.09 & $41 \%$ & $28 \%$ & $34 \%$ & 340 \\
\hline 2018 & 96 & 106 & 101 & 1.11 & $44 \%$ & $25 \%$ & $34 \%$ & 660 \\
\hline
\end{tabular}

\section{Lobster length distribution}

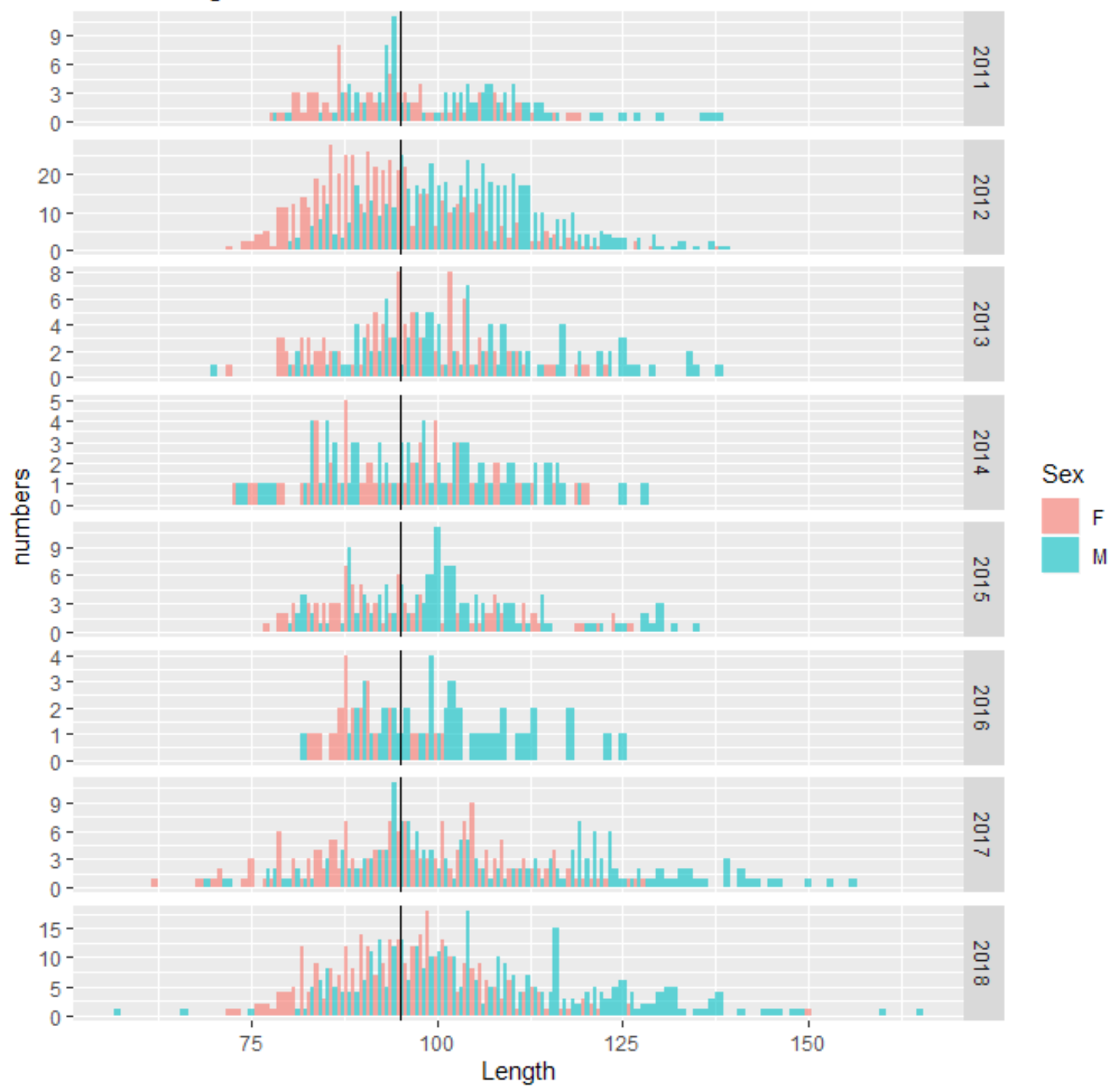

Figure 8. Yearly length frequency distribution per sex of lobster landings (vertical line depicts the minimum landing size). 


\subsubsection{Mixed fish landings}

\section{Species composition}

The species composition of the reef fish landings is very diverse, as shown by the large proportion of the species representing less than $5 \%$ of the landings ("other"). Acanthuridae (Blue tang, Acanthurus coeruleus, Doctorfish, A. chirurgus, Surgeonfish, A. oceanus), Ostraciidae (honeycomb Acanthostracion polygonius and scrawled filefish, Aluterus scriptus) and Serranidae (Coney, Cephalopholis fulva and Red hind, Epinephelus guttatus) are the most abundant in the landings, representing, 31\%, $19 \%$ and $12 \%$ of the landings, respectively.

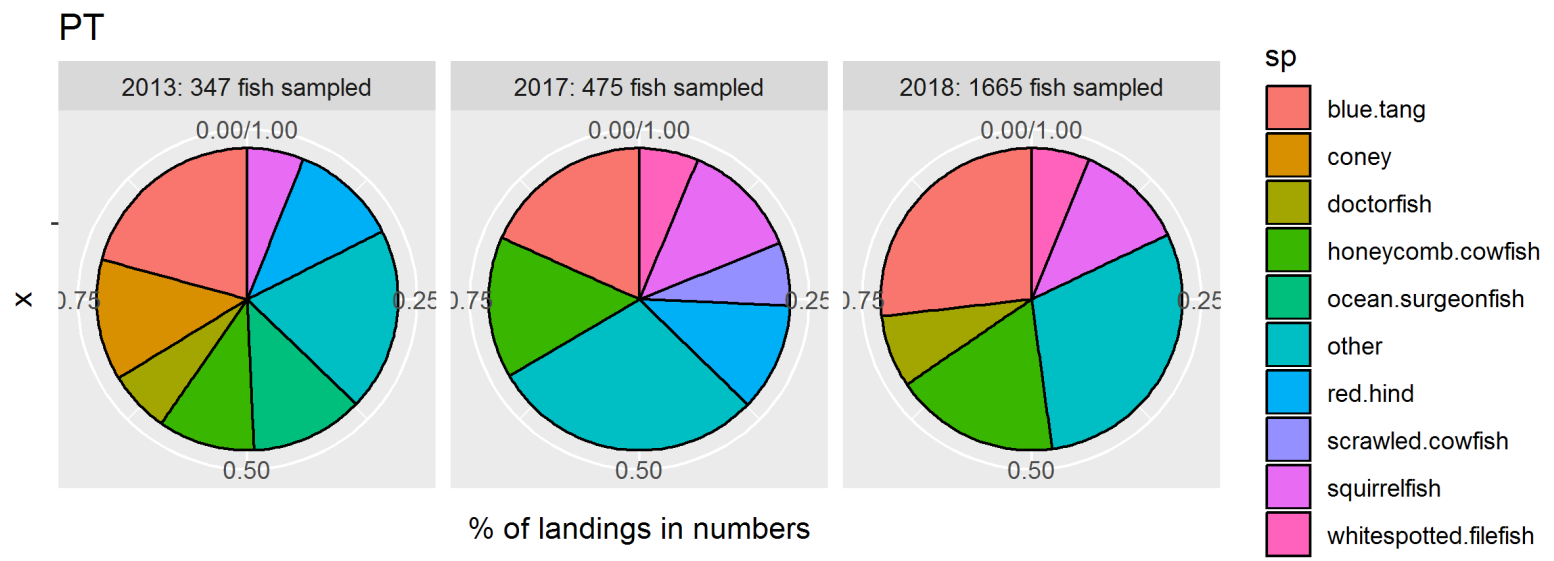

Figure 9. Species composition in number of the reef fish landed from the lobster trap fishery.

\section{CPUE standardisation using a GLM model}

The low CPUE for the reef fish in the trap fishery is shown in annex 2. Unlike for the lobster, no clear seasonal pattern was visible. The GLM model was fitted to estimate the influence of different factors on the CPUE, and to extract an abundance index. For reef fish, there is no significant effect of the number of traps set (Table 5), but the effect of soaking time is significant (decreasing number of fish caught with increasing soaking time). The month effect is also significant, but mainly due to the lower CPUE for the month of September compared to the rest of the year (figure 10). The year effect indicates an increase in the abundance in 2013-2014 compared to the rest of the time period.

Table 5. Significance of each model term tested by removing them step-wise and comparing to the full model (GLM model of reef fish landings per trip). See table 3

\begin{tabular}{|c|c|c|c|c|c|}
\hline Model term removed & $\begin{array}{l}\text { Number of } \\
\text { parameters }\end{array}$ & AIC & $\begin{array}{l}\text { Log- } \\
\text { Likelihood } \\
\text { ratio }\end{array}$ & p.value & $\begin{array}{l}\text { Signif. } \\
\text { level }\end{array}$ \\
\hline <none $>$ & & 1290.7 & & & \\
\hline factor (Year) & 6 & 1301.9 & 3.7899 & 0.001060 & $\star \star$ \\
\hline factor (Month) & 11 & 1293.2 & 2.1833 & 0.014237 & * \\
\hline factor (Boat_name) & 3 & 1301.8 & 5.5638 & 0.000925 & $\star \star$ \\
\hline Soaking_time_days & 1 & 1299.5 & 10.4621 & 0.001300 & $\star \star$ \\
\hline logTraps & 1 & 1291.4 & 2.6182 & 0.106283 & \\
\hline
\end{tabular}



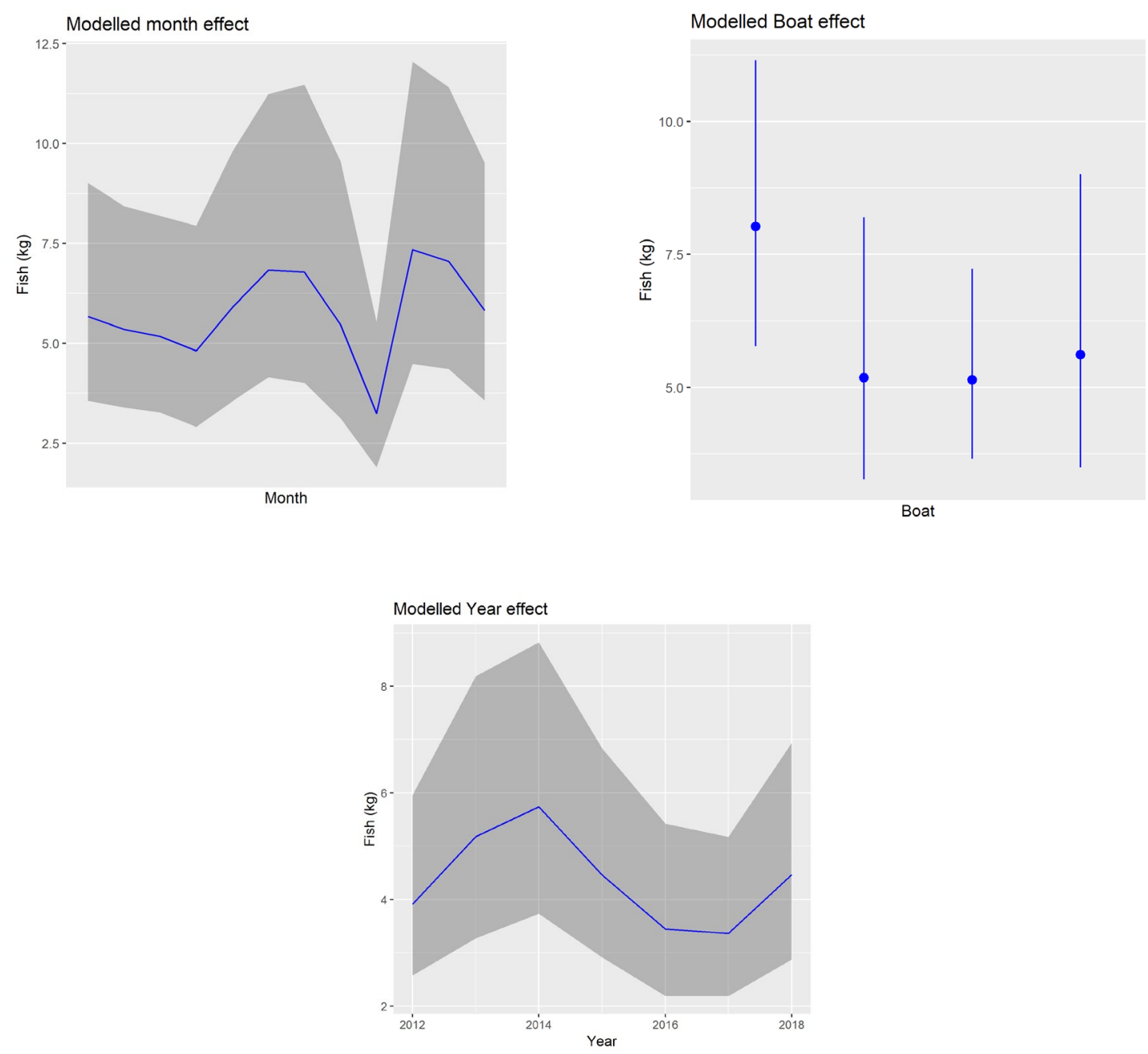

Figure 10. Modelled month effect and year effects on the landings of reef fish from the trap fishery per trips (in numbers). Blue lines represent the modelled effect (and associated 95\% uncertainty in grey).

\section{Length frequency distribution of the landings}

The length frequency composition of the landings of the reef fish caught in the traps are given in annex 3 for the main species. Although some length measurements are taken from the landings of other gears, the majority of the samples are from the trap fishery. Data for the other gears are not displayed in this report as they are too scarce to give an accurate representation of landings length composition per species.

For most species the mean length is stable over time. The stoplight parrotfish is an exception, with a notably lower mean length in 2012 than for the rest of the period. 


\subsection{Diving}

\subsubsection{Fishing activity}

The activity of boats conducting scuba diving trips is divided between trips targeting lobster and reef fish, and trips in which conch is the target. Conch represents the totality of the landings for $25 \%$ of the trips (right part of Figure 11), while it is absent from the landings for $54 \%$ of the trips (left part of Figure 11). For the remaining $21 \%$ of the trips with a mix of conch, lobster and reef fish, the proportion of conch in the landings is generally high.

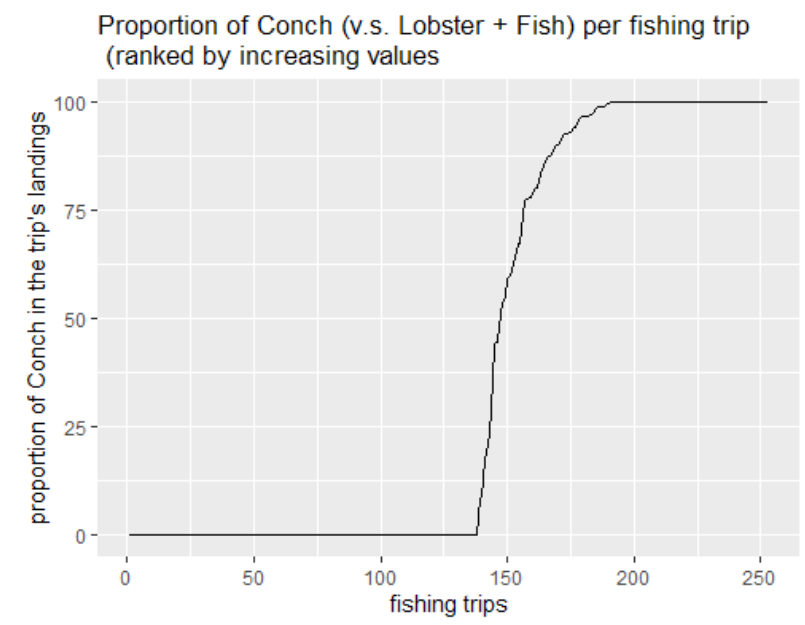

Figure 11. Distribution of the proportion of conch in the landings of scuba diving trips.

\subsubsection{Mixed Lobster / reef fish fishery}

\section{Species composition}

Lobster represents the vast majority of the landings for free diving (Figure 12), while lobster and reef fish contribute almost equal shares in the landings for the scuba diving fishery (for the trips not targeting conch).
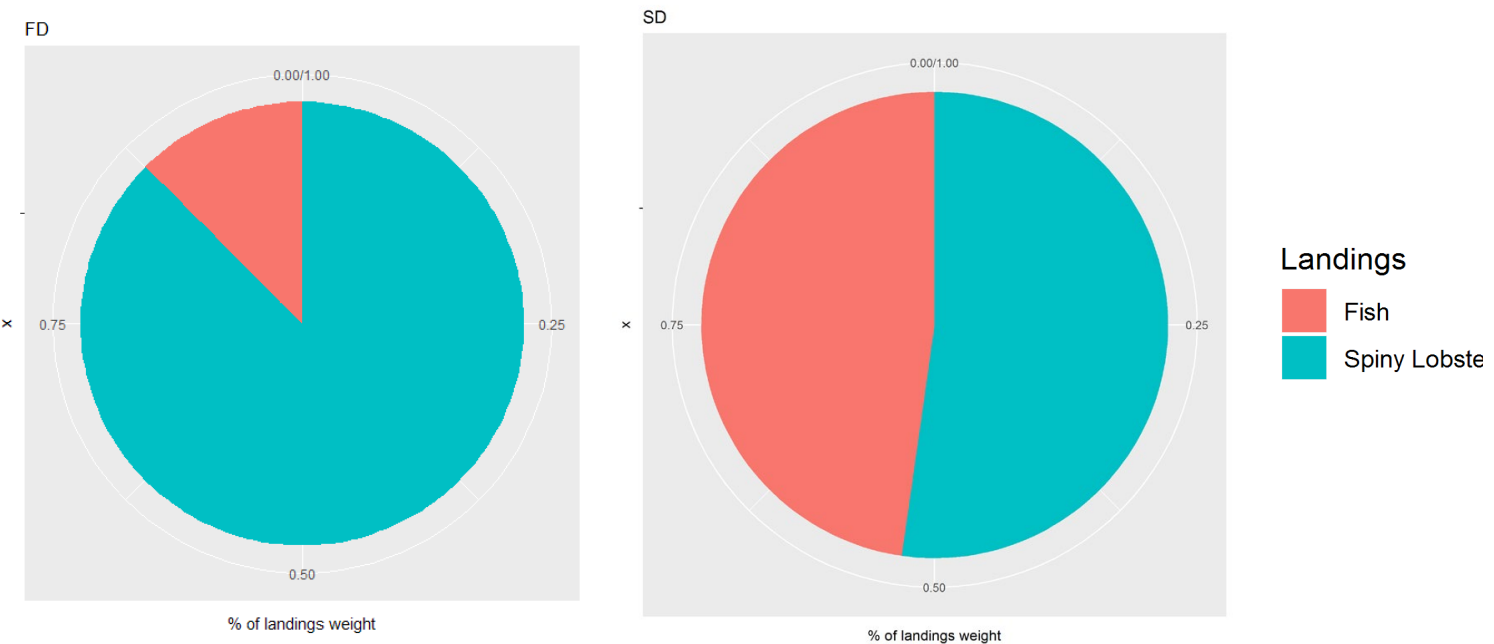

Figure 12. Average proportion of lobster and reef fish in the landings in weight of the free diving (FD) and scuba diving (SD) fishery over the period 2012-2018. 
Landings from scuba diving were well-sampled in 2017 and 2018. The main species caught were Serranidae (Coney and Red hind), representing nearly half of the landings (Figure 13). The fishery also lands a fair proportion of Lionfish, Pterois volitans, and of different parrotfish (Scaridae). The category "other" (species that represent less than 5\%) is also large, indicating that a large number of species have a small contribution to the total landings.

Very little information was collected on the composition of the reef fish landings from free diving, and these are not presented here.

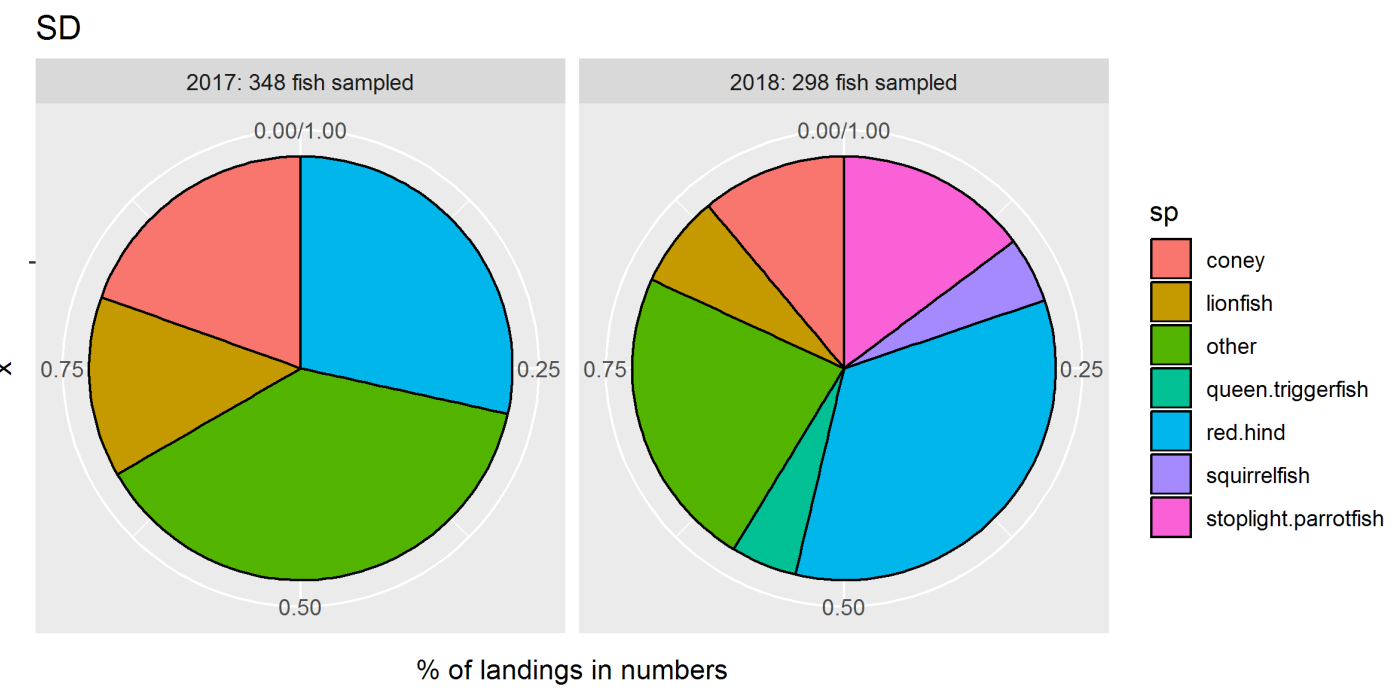

Figure 13. Landings species composition (based on fish numbers) for the scuba diving fishery.

\section{CPUE standardisation using a GLM model for lobster landings}

Due to the scarcity of the data from the scuba diving fishery in some months (figure 5), a single GLM model was fitted including both scuba and free diving trips. The effect of the metier - free or scuba diving - was included in the model. No month effect was included in the model, as the sampling did not cover all months. The effort was represented here by the number of diving hours (diving time multiplied by the number of divers). In the full model, including all effects (Table 6), only the diving time had an effect (positive) on the landings of lobster. Removing the non-significant effect one by one, the final model included both the year-effect and the diving-time effect (Figure 14). The year-effect indicates an increase in abundance from 2013 to 2016, and a rapid decrease in 2017 and 2018. This pattern is broadly in agreement with the analyses on the trap data for the period 2012-2016, where both indices indicate an increasing abundance. However, the decline post 2016 in the diving fishery abundance index only occurs after 2017 in the trap fishery, and is of a lesser magnitude.

\section{CPUE standardisation using a GLM model for the reef fish landings}

The logbook data available was too scarce to conduct an analysis of the CPUE for the reef fish landings. 
Table 6. Significance of each model term tested by removing them stepwise and comparing to the full model (GLM model of lobster landings per trip). See table 3.

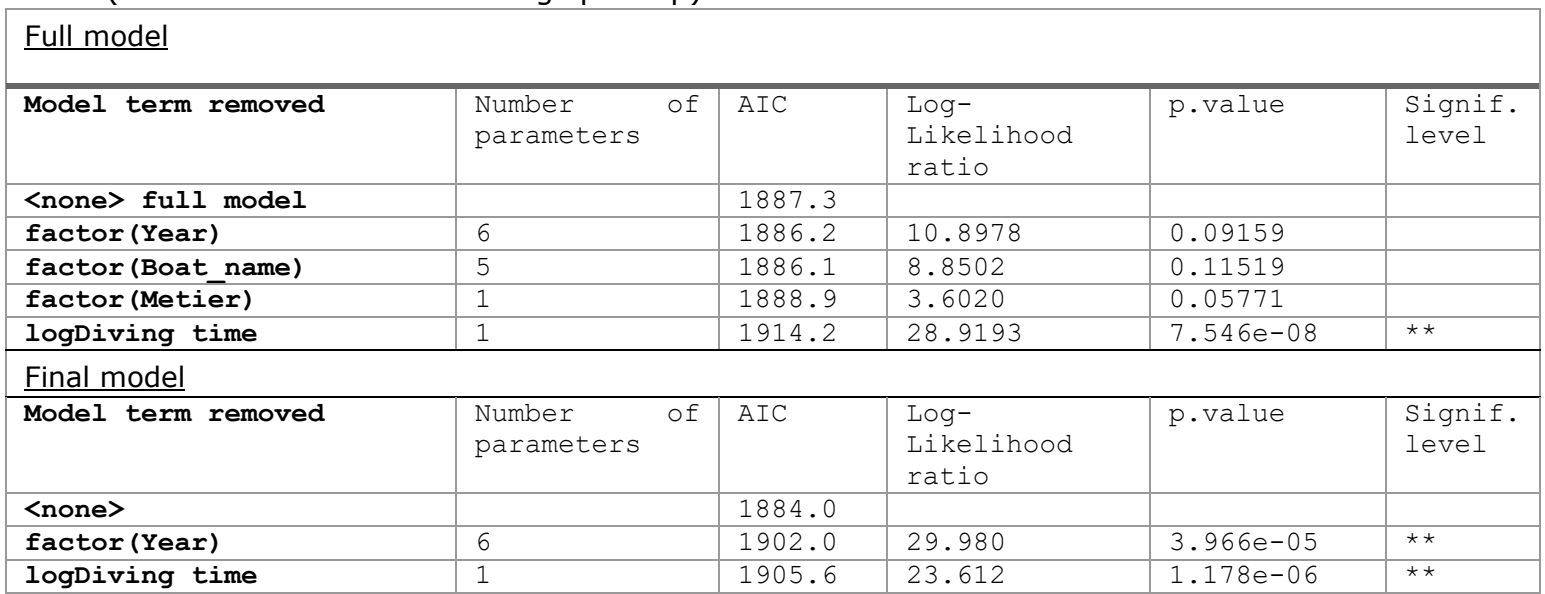
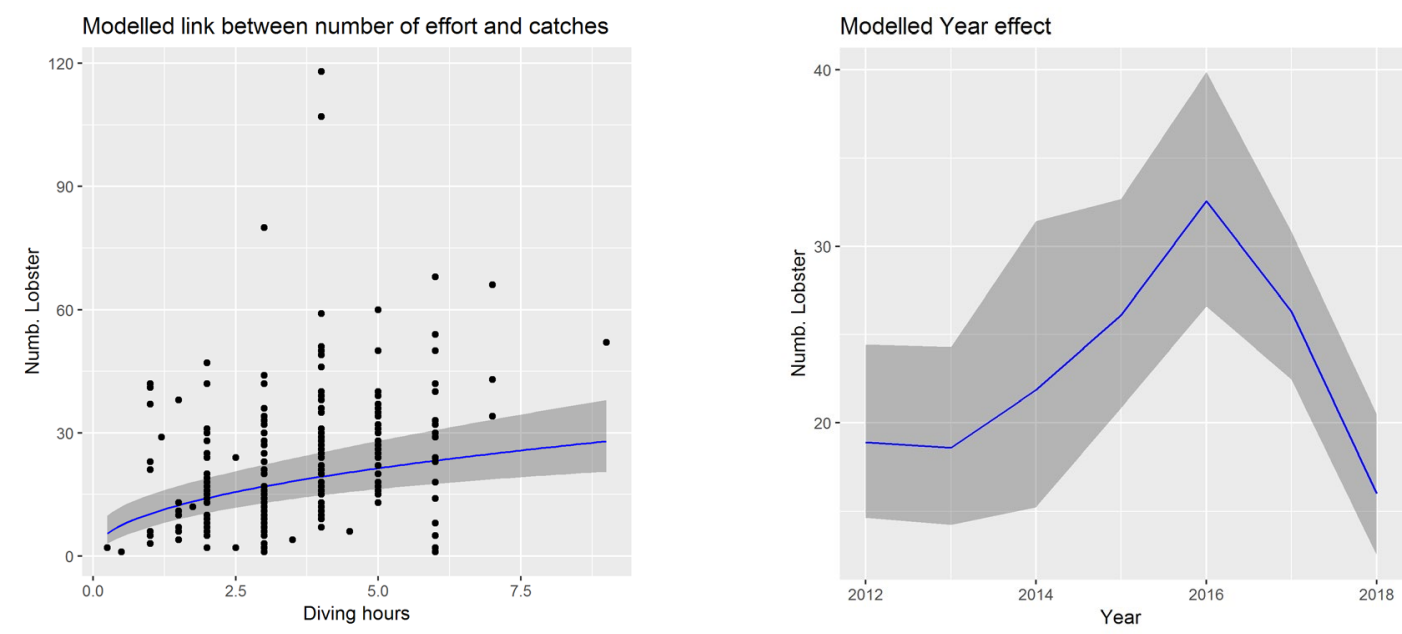

Figure 14. Modelled effect of fishing effort (diving hours per trip) and year effects on the landings of lobsters in diving fisheries per trip (in numbers). Blue lines represent the modelled effect (and associated $95 \%$ uncertainty is in grey).

\subsubsection{Conch fishery}

\section{GLM modeling of conch landings per trips}

The landings of conch per trips were also modeled using GLM. The full model included the effect of Year, Month, and of the number of diving hours during the trips. Boats for which data was available changed over the years and it was therefore not possible to include a boat effect in the model. Removing one by one the non-significant term of the model, the final model only included the year effect (table 7). The year effect shows a period of lower abundance in 2014-2015, followed by an increase until 2017 and a decrease in 2018 (Figure 15). 
Table 7. Significance of each model term tested by removing them one by one and comparing to the full model (GLM model of conch landings per trip). See table 3.

\begin{tabular}{|c|c|c|c|c|c|}
\hline \multicolumn{6}{|l|}{ Full model } \\
\hline Model term removed & $\begin{array}{ll}\text { Number } & \text { of } \\
\text { parameters } & \end{array}$ & AIC & $\begin{array}{l}\text { Log- } \\
\text { Likelihood } \\
\text { ratio }\end{array}$ & p.value & $\begin{array}{l}\text { Signif. } \\
\text { level }\end{array}$ \\
\hline <none> full model & & 1049.9 & & & \\
\hline factor (Year) & 6 & 1050.7 & 12.8196 & 0.04599 & * \\
\hline \multicolumn{6}{|l|}{ Final model } \\
\hline Model term removed & $\begin{array}{ll}\text { Number } & \text { of } \\
\text { parameters } & \end{array}$ & AIC & $\begin{array}{l}\text { Log- } \\
\text { Likelihood } \\
\text { ratio }\end{array}$ & p.value & $\begin{array}{l}\text { Signif. } \\
\text { level }\end{array}$ \\
\hline
\end{tabular}

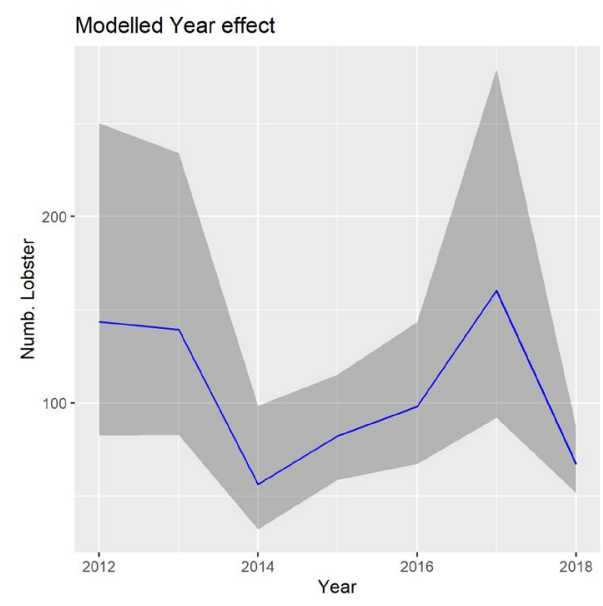

Figure 15. Modelled year effects on the landings of conch in scuba diving fisheries per trips (in numbers). Blue lines represent the modelled effect (and associated $95 \%$ uncertainty in grey).

\section{Landings lip thickness and shell length composition}

Lip thickness and shell length measurements of the landings of conch were available for the period 2012-2018, with exception of the year 2014. There are some variations observed between years in the both mean lip thickness and mean shell length, but with no clear trend (figure 16). Mean lip thickness varies between $24.8 \mathrm{~mm}$ and 27.2 (in 2017 and 2015, respectively). The range of variation for mean shell length is small (half centimeter maximum difference in the annual mean for both sexes combined). The difference between sexes in mean lip thickness are for most years not significant, except in 2016 when lip thickness was markedly lower for females than for males. The females landed tend to be larger than the males, by approximately $1 \mathrm{~cm}$.
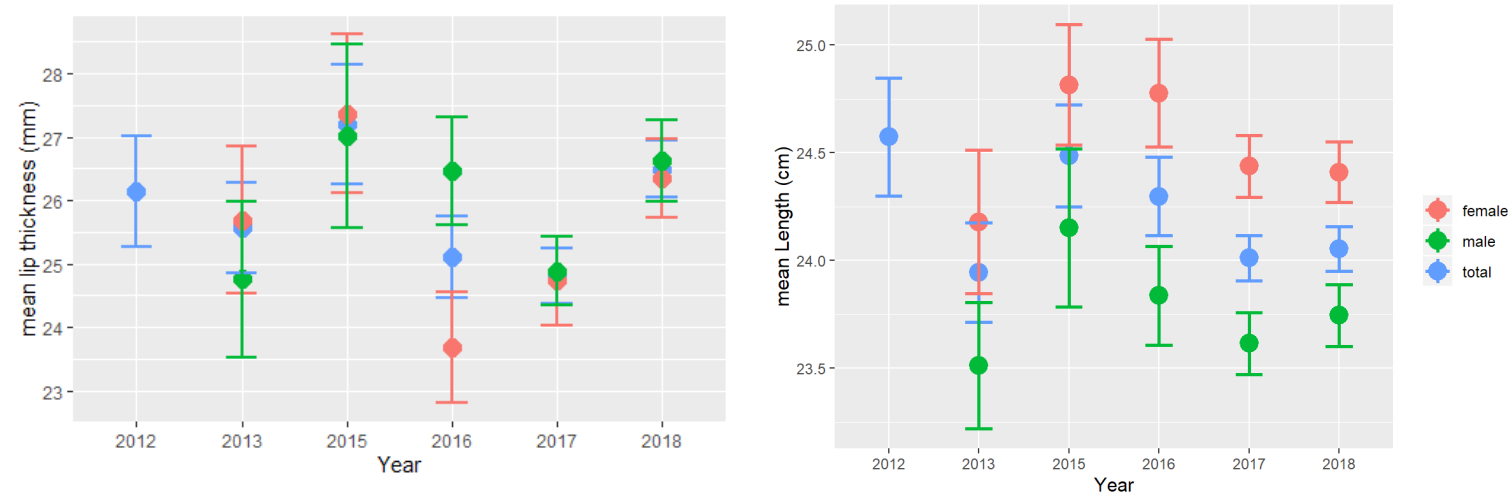
Figure 16. Mean lip thickness (left) and length (right) of conch from the landings (per sex and for sexes combined).

\subsection{Handlines}

\subsubsection{Species composition of the landings}

Species composition data for the handline fishery was scarce, and covers only 4 trips in 2017 (Figure 17). Two of these trips caught only bigeye scad, Selar crumenopthalmus, while the other two mostly caught Serranidae. These two sampled trips actually correspond to two different types of fishery, one on smaller pelagic fish, the other on large pelagic fish.

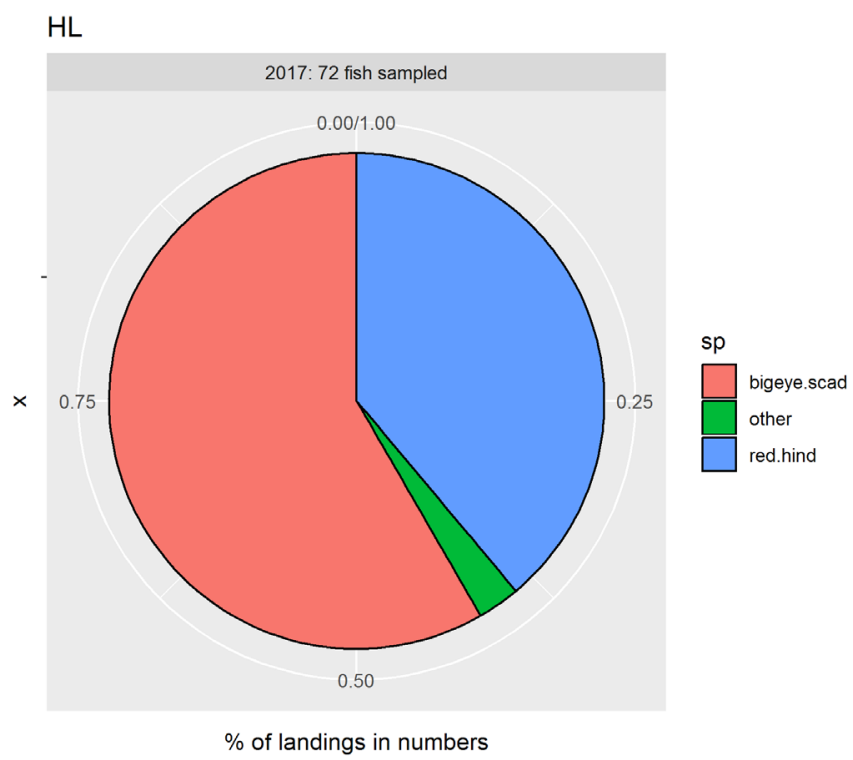

Figure 17. Species composition of the landings of the handline fishery (in weight) for the fish species only

\subsubsection{CPUE standardisation using a GLM model}

The effort of the handline fishery was represented in the CPUE analysis by both the duration of the fishing operation and by the number of lines used. In the full model, including all effects (Table 7), only these 2 terms (length of time and number of lines), related to the effort, were significant (positive effect). Removing the non-significant effects one by one, the final model includes a boat effect in addition to the effect of the effort related variables (Table 8 and Figure 18). The year effect not being significant indicates that in none of the years the abundance was different from the other years. 
Table 8. Significance of each model term tested by removing them stepwise and comparing to the full model (GLM model of reef fish landings per trip). See table3.

\begin{tabular}{|c|c|c|c|c|c|}
\hline \multicolumn{6}{|l|}{ Full model } \\
\hline Model term removed & $\begin{array}{ll}\text { Number } & \text { of } \\
\text { parameters } & \end{array}$ & AIC & $\begin{array}{l}\text { Log- } \\
\text { Likelihood } \\
\text { ratio }\end{array}$ & p.value & $\begin{array}{l}\text { Signif. } \\
\text { level }\end{array}$ \\
\hline <none> & & 294.14 & & & \\
\hline factor (Year) & 6 & 286.68 & 0.6134 & 0.7190 & \\
\hline factor (Month) & 11 & 280.47 & 0.6235 & 0.8042 & \\
\hline logDur & 1 & 340.01 & 47.4527 & $8.059 e-10$ & $\star \star$ \\
\hline \multicolumn{6}{|l|}{ Final model } \\
\hline$\overline{\text { Model term removed }}$ & $\begin{array}{ll}\text { Number } & \text { of } \\
\text { parameters } & \end{array}$ & AIC & $\begin{array}{l}\text { Log- } \\
\text { Likelihood } \\
\text { ratio }\end{array}$ & p.value & $\begin{array}{l}\text { Signif. } \\
\text { level }\end{array}$ \\
\hline logDur & 1 & 336.99 & 81.2116 & $1.006 e-14$ & $\star \star$ \\
\hline
\end{tabular}
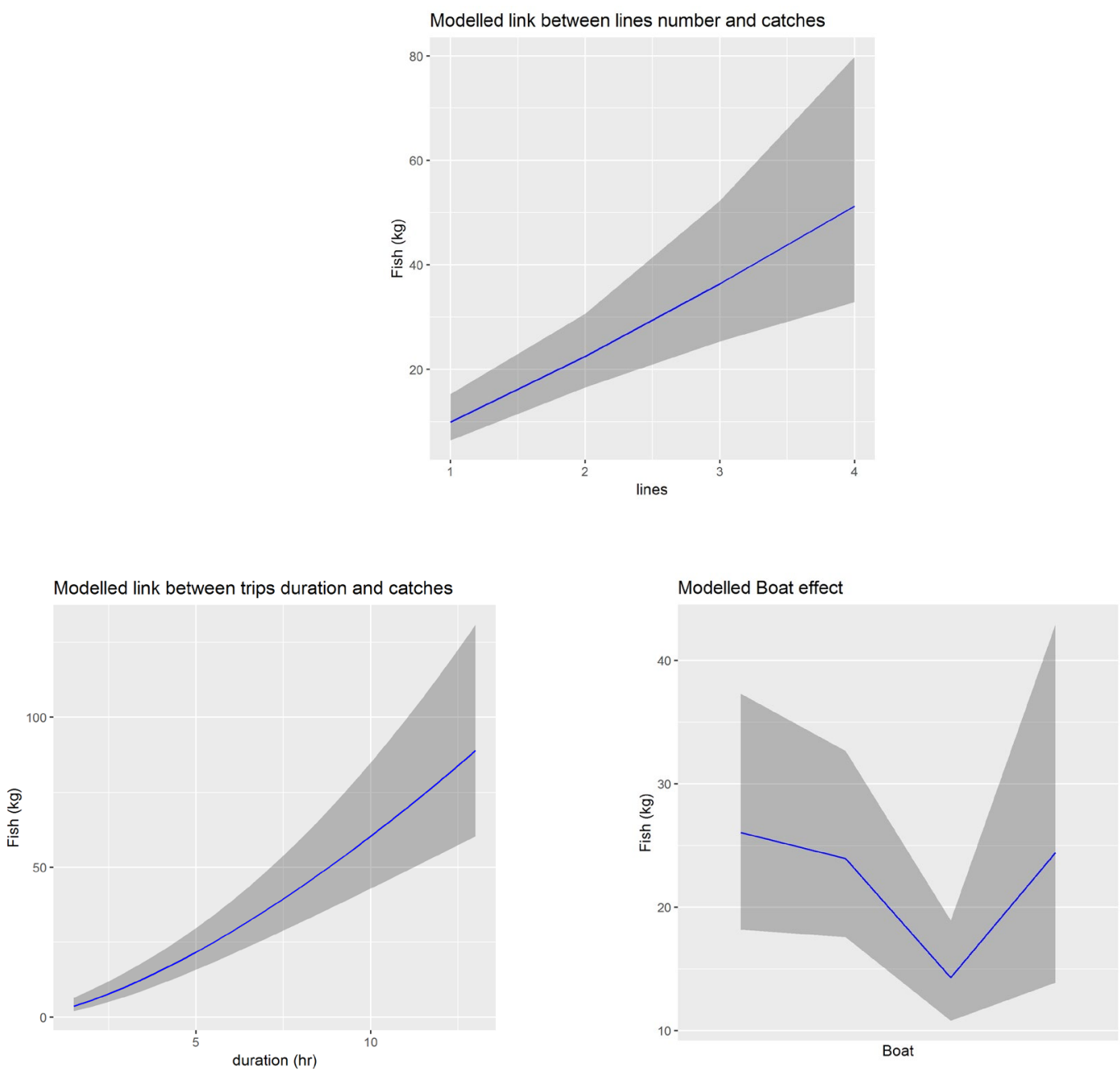

Figure 18. Modelled effect of fishing effort (number of lines and duration) and boat effect on the landings of reef fish from the handline fisheries per trips (in numbers). Blue lines represent the modelled effect (and associated $95 \%$ uncertainty in grey). 


\subsection{Trolling}

\subsubsection{Species composition of the landings}

The two most abundant species in the landings of the trolling fishery are dolphin fish, Coryphaena hippurus, and houndfish, Tylosurus crocodilus, depending on the year.

TR
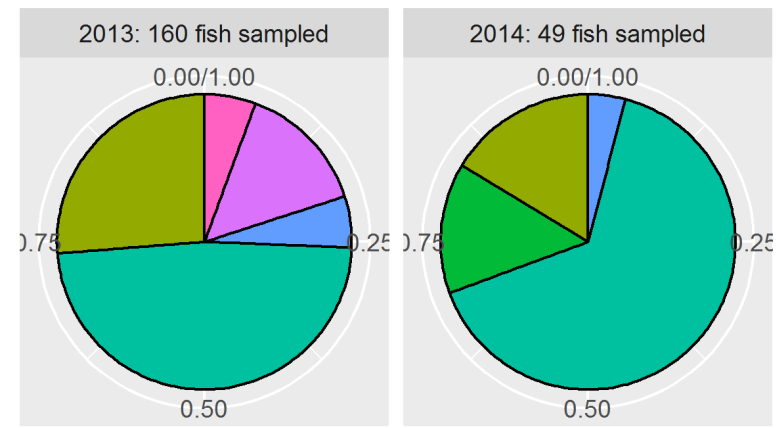

$\times$
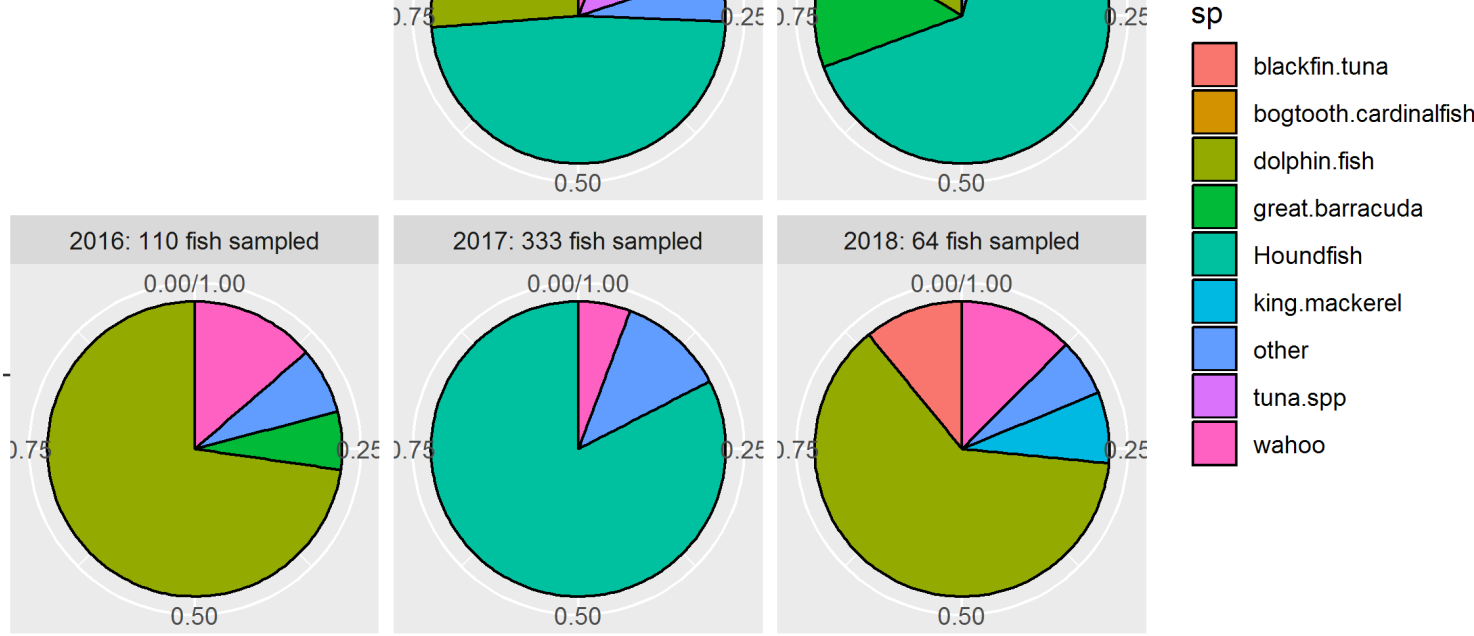

$\%$ of landings in numbers

Figure 19. Yearly species composition of the landings of the trolling fishery (in weight) for the fish species.

\subsubsection{CPUE standardisation using a GLM model}

As for the handline fishery, the effort was represented by the number of lines and the duration of the fishing operation in the CPUE analysis. In the full model, including all effects (Table 9), only the boat effect was significant. Removing the none significant effects one by one, the final model includes a boat effect and a year effect (Table 8 and Figure 20). The year effect gives indication of a globally increasing abundance over the period covered by the study. 
Table 9. Significance of each model term tested by removing them one by one and comparing to the full model (GLM model of reef fish landings per trip). See table 3.

\begin{tabular}{|c|c|c|c|c|c|}
\hline \multicolumn{6}{|l|}{ Full model } \\
\hline Model term removed & $\begin{array}{l}\text { Number of } \\
\text { parameters }\end{array}$ & AIC & $\begin{array}{l}\text { Log- } \\
\text { Likelihood } \\
\text { ratio }\end{array}$ & p.value & $\begin{array}{l}\text { Signif. } \\
\text { level }\end{array}$ \\
\hline <none & & 637.33 & & & \\
\hline factor (Year) & 6 & 640.20 & 1.9444 & 0.079719 & \\
\hline factor (Month) & 11 & 637.55 & 1.6255 & 0.100934 & \\
\hline factor (Boat_name) & 18 & 653.65 & 2.5971 & 0.001203 & * \\
\hline logLines & 1 & 635.50 & 0.1214 & 0.728216 & \\
\hline logDur & 1 & 637.94 & 1.9619 & 0.164075 & \\
\hline \multicolumn{6}{|l|}{ Final model } \\
\hline Model term removed & $\begin{array}{l}\text { Number of } \\
\text { parameters }\end{array}$ & AIC & $\begin{array}{l}\text { Log- } \\
\text { Likelihood } \\
\text { ratio }\end{array}$ & p.value & $\begin{array}{l}\text { Signif. } \\
\text { level }\end{array}$ \\
\hline <none> & & 642.39 & & & \\
\hline factor (Year) & 6 & 652.73 & 3.3503 & 0.0042496 & $\star \star$ \\
\hline factor (Boat_name) & 18 & 654.93 & 2.6543 & 0.0007979 & $\star \star$ \\
\hline
\end{tabular}
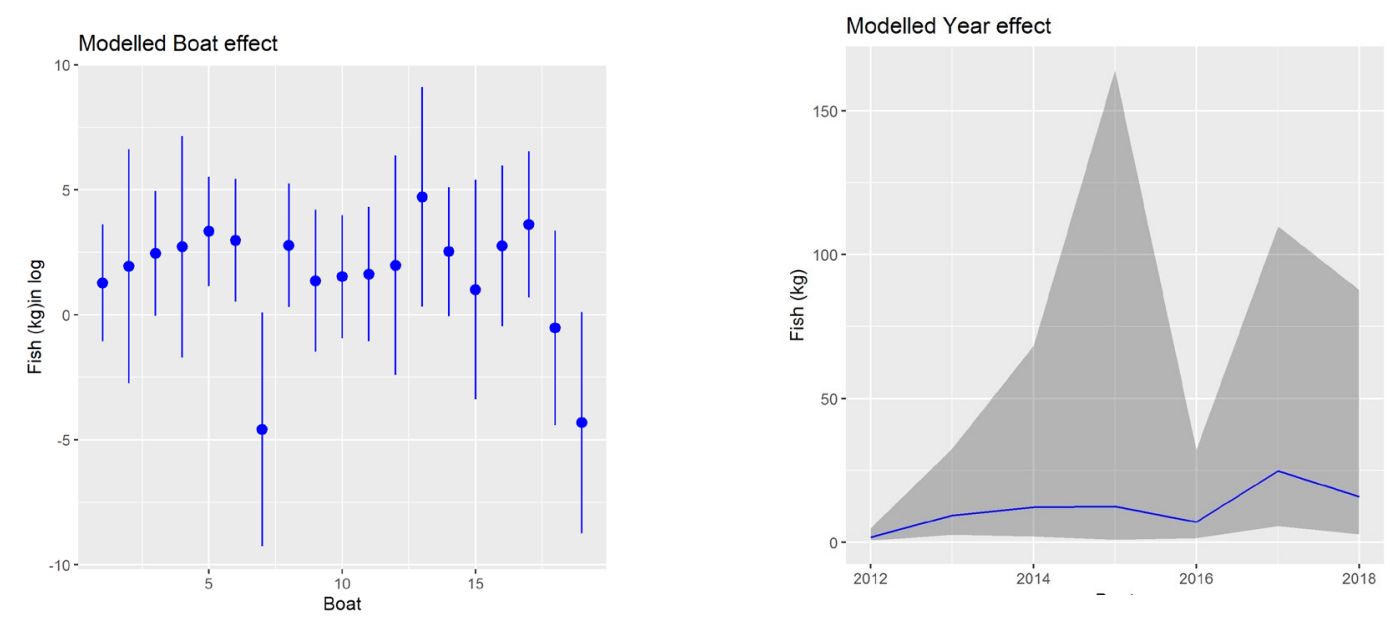

Figure 20. Modelled boat and year effects on the landings of pelagic fish from the trolling fisheries per trips (in weight). Blue lines represent the modelled effect (and associated $95 \%$ uncertainty in grey). 


\section{Discussion}

De Graaf et al. (2015) analyzed an earlier version of the St Eustatius fisheries database. They estimated an average annual landings over the years 2012-2015 of 11 tonnes for lobsters, 3.8 tonnes for reef fish and 0.8 tonnes of pelagic fish. They report an average number of $\sim 500$ trips per year over this period. The analyses presented here estimate much higher annual landings over the same period, which is mostly explained by the much higher effort estimated (1,001 trips per year). This nearly two-fold difference in effort between the current study and de Graaf et al. (2015) is due to the raising done in this report to take account of the incomplete coverage of the boat activity survey (i.e. activity data covering about 50\% the active days in the month in 2012-2017, Figure 1 ). This correction was not done in the 2015 study.

The later preliminary study of Kitson-Walters (2018) focusing on the year 2017 estimated annual landings of lobster and fish of 52 and 17 tonnes, respectively. Those were substantially higher than the estimates for the same year from the present study of 25 and 9 tonnes, respectively. Estimates of effort and landings from 2017 should be considered with caution, because of the lack of boat activity survey for the last 3 quarters of the year. Both studies attempted to palliate for the lack in the effort data by inferring boat activity from the logbook data, but in both cases, the methods used come with high associated uncertainties.

More generally, given the many gaps in the data, any attempt to estimate catches has to make doubtful assumptions and such calculations should be considered as highly uncertain. The main assumptions that were made in the present study were :

- $\quad$ Boat activity for the days without activity survey is similar to the activity for the days with survey. This extrapolation represents more than 50\% of the effort over the period 2012-2017.

- $\quad$ The proportion of the fishing time allocated to the different fishing methods and the resulting landings per trip are the same for the boats providing logbooks and for those not providing logbooks (this extrapolation represents between $30 \%$ and $50 \%$ of the boats, depending on the year).

The coverage of the activity survey has markedly increased in the last year of the period studied here (Figure 1), and has been close to $100 \%$ in 2019 . This is a positive development, which, if sustained, will result in a much better quantification of the fishing effort. Even so, for several of the fishing metiérs, the number of catches quantified (in terms of totals caught) and species specific subsampling for species composition and size-structure data remain very low (Table 1) and variable, with as a consequence that the confidence/credibility of the results remain seriously compromised. For conch and lobster the samples sizes are the best.

The precision of the catch estimates could be improved by increasing the number of boats delivering logbooks. Given the diversity of fishing patterns observed in the available logbooks (i.e. distribution of fishing time between different fishing methods), and also given the significant boat effect in most GLM models, it seems necessary to increase the number of boats delivering logbooks.

The St Eustatius lobster fishery (with between 16 and 48 tonnes caught annually) contributes a very small fraction of the regional total annual landings of spiny lobster for the Caribbean $(30,000$ tonnes, de Graaf et al. 2015). However, considering the small size of the fishing area, these landings correspond to a production of at least $500 \mathrm{~kg} / \mathrm{km}^{2}$ annually, one the highest reported in the Caribbean (Table 4.1 from de Graaf et al. 2015). De Graaf et al. (2015) bring forward the hypothesis that high yields on St Eustatius may be related to a naturally high productivity in this area, explained by a combination of large nursery areas and unlimited recruitment of pelagic larvae from most likely other Caribbean islands. However, they also note that such high yields per km2 have only been observed in the Caribbean during the developing phase of the lobster fishery between 1970 and 1990, as based on overfishing, and consider it doubtful that these high landings were sustainable. 
The individual size of the lobsters landed may be a reason for concern. Average size of landed lobster was $95 \mathrm{~mm}$ and $102.5 \mathrm{~mm}$ for females and males respectively and $41 \%$ of the landed lobsters were under the minimum legal size of $95 \mathrm{~mm} \mathrm{CL}$. This problem is even more severe for females, for which $56 \%$ are harvested below the legal size. Dilrosun (2004) measured 43 harvested lobsters in November 2003 and reported an average length of $110 \mathrm{~mm} \mathrm{CL}$, well above the minimum legal size. It is important to understand why undersized lobsters are now being landed by the fishermen. Do the fishermen intentionally target smaller individuals to answer a market demand for plate-sized undersized lobsters? If not, the small size of the lobsters currently landed on St Eustatius could indicate a truncation of the age/size structure of the population towards younger/smaller individuals, which would suggest that the stock is overexploited.

Abundance indices for lobster calculated from the landings per trips in the trap and scuba fisheries give slightly different perceptions of the trends in the stock. This can potentially be explained by the fact that both fisheries operate at different depths (e.g. $\sim 30 \mathrm{~m}$ for the traps v.s $\sim 14 \mathrm{~m}$ for free diving) and therefore potentially exploit different parts of the population (age groups, areas). Both indices indicate first an increase followed by a decrease of the stock over the period 2012-2018, but the decrease occurs one year earlier (2017) for the index based on the catches from diving, and is of a much larger magnitude. Because of this limited agreement between the two indices, and because of the short length of the time period studied, it is difficult to draw conclusions about the existence of any trend in the lobster stock. Furthermore, in absence of any reference value (such as a biomass reference point at Maximum Sustainble Yield) the actual state of the stock (under/over exploitation) remains unknown. Continuation of a robust fishery monitoring (catch, effort, length frequency) is needed to provide fishery dependent indices (time series) that could be used to provide a more accurate assessment of the stock and, thereby, a better basis for management. With respect to the lobster fishery, we conclude that the apparent decline in lobster abundance in 2018 (based on the lobster pot CPUE index) and persistent high landing rate of sublegal-sized lobsters (discussed above) is worrisome. While, given all the uncertainties in the data, it would seem premature to already conclude that there is actual overfishing taking place, it does seem that the early signs might already be there. Therefore in any case the lobster catches should be monitored with more precision and with caution and the landing of sublegal lobsters needs to be controlled with better enforcement.

Serranidae are typically among the most valuable commercial reef fish species. While the mixed fish catch from the lobster trap fishery are dominated by low-value Acanthuridae and Ostraciidae, two Serranid species (Coney, Cephalopholis fulva and Red Hind, Epinephelus guttatus) jointly still make up $12 \%$ of the total trap landings weight. The Coney is a small species, whereas the Red Hind is a mediumsized grouper and the most vulnerable of the two to overfishing. This latter species has even disappeared from catches in various areas of the Caribbean (Debrot and Criens 2005, Vermeij et al. 2019, Debrot et al. 2020). For St Eustatius, de Graaf et al. 2015 indicated both of these species to likely be seriously over-exploited. The amount of data on these species and other low-value bycatch species like parrotfish and Doctorfish from the current port sampling activity is limited and patchy. Hence, more intensive port sampling data and additional fishery-independent study of these two species of value and concern are certainly to be recommended. Likewise, the data on the handlining, trolling and the newly developing FAD fishery (next paragraph) are so few and scattered that a significant analysis of trends does not yet seem warranted. In our concluding recommendations we do include the recommendation to intensify catch sampling for these metiérs as well.

Finally, of particular concern is the fact that an unofficial Fish Attracting Device (FAD) fishery has been developing around St. Eustatius, but data on this fishery are not yet available. This fishery targets pelagic fish species as also already caught in the small trolling fishery. These species are totally different from those caught in the traditional and predominant reef-based fishery. FAD fisheries have proven very problematic elsewhere, leading to cases of severe overfishing and serious disputes between fishermen (Samples and Sproul 1985, CRFM 2015, Sadusky et al. 2018). There is an urgent need to obtain data from this new development and to guide the development of this fishery. While FAD fishing likely presents valuable opportunities for further fisheries development in St. Eustatius (see also recommendations for Bonaire: Debrot and van den Berg 2019), it should be managed and contained, not only to allow it to develop to its full potential but also to avoid the many pitfalls associated with this form of fishing (Figure 21). 


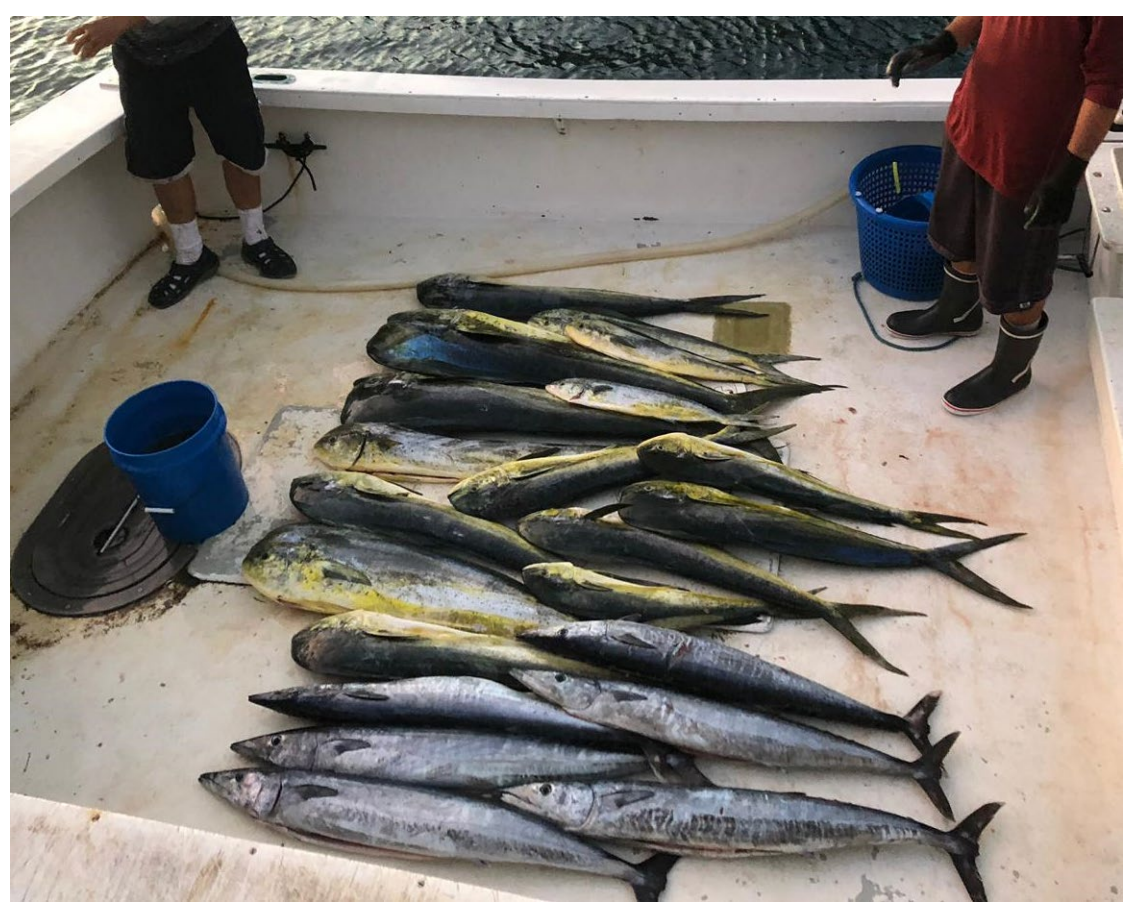

Figure 21. Example of FAD catch from nearby Saba. (Photo: Ayumi Kuramae).

In conclusion, our main recommendations in terms of both management and research and monitoring are:

Management:

- Improve control of and compliance with lobster size-limit regulations.

- Develop a FAD fishery management plan as part of a St. Eustatius fisheries development plan.

\section{Research and monitoring:}

- Improve port sampling (for overall catch recording) and subsampling (for size-frequency data) intensity to cover at least one third of the trips dedicated to each key fishing metiér (these are the following fisheries metiérs: lobster pot, conch, spearfishing, trolling, FAD fishery). At present we are jointly developing better guidelines for these port sampling activities.

- Conduct a closer study on both the Coney and the Red Hind. Do this by combining more intensive port sampling and fisheries independent studies on the distribution and abundance of these species around St. Eustatius. 


\section{Quality Assurance}

Wageningen Marine Research utilises an ISO 9001:2015 certified quality management system. This certificate is valid until 15 December 2021. The organisation has been certified since 27 February 2001. The certification was issued by DNV GL.

Furthermore, the chemical laboratory at IJmuiden has EN-ISO/IEC 17025:2017 accreditation for test laboratories with number L097. This accreditation is valid until $1^{\text {th }}$ of April 2021 and was first issued on 27 March 1997. Accreditation was granted by the Council for Accreditation. The chemical laboratory at IJmuiden has thus demonstrated its ability to provide valid results according a technically competent manner and to work according to the ISO 17025 standard. The scope (L097) of de accredited analytical methods can be found at the website of the Council for Accreditation (www.rva.nl).

On the basis of this accreditation, the quality characteristic $Q$ is awarded to the results of those components which are incorporated in the scope, provided they comply with all quality requirements. The quality characteristic $Q$ is stated in the tables with the results. If, the quality characteristic $Q$ is not mentioned, the reason why is explained.

The quality of the test methods is ensured in various ways. The accuracy of the analysis is regularly assessed by participation in inter-laboratory performance studies including those organized by QUASIMEME. If no inter-laboratory study is available, a second-level control is performed. In addition, a first-level control is performed for each series of measurements.

In addition to the line controls the following general quality controls are carried out:

- Blank research.

- Recovery.

- Internal standard

- Injection standard.

- Sensitivity.

The above controls are described in Wageningen Marine Research working instruction ISW 2.10.2.105. If desired, information regarding the performance characteristics of the analytical methods is available at the chemical laboratory at IJmuiden.

If the quality cannot be guaranteed, appropriate measures are taken. 


\section{References}

CRFM. 2015. 2015 Draft Sub-Regional Management Plan for FAD Fisheries in the Eastern Caribbean (Stakeholder Working Document). CRFM Technical \& Advisory Document. 94p.

Debrot, A.O., Brunel, T., Schop, J., Kuramae, A., Bakkers, Y. 2020. Assessing effectiveness of the seasonal closure of the Moonfish Bank of the Saba Bank for two species of concern, the Red Hind and the Queen Triggerfish: the first five years. WMR report.

Debrot, A. O., S. R. Criens 2005. Reef fish stock collapse documented in Curaçao, Netherlands Antilles, based on a preliminary comparison of recreational spear fishing catches half a century apart. 32nd AMLC (Abstract)

Debrot, D. (A.O.), and S. van der Burg. 2019. Food from the Oceans. Factsheet 3. Nexus interventions for small tropical islands: case study Bonaire. 9 pp. In: Slijkerman, D. and M. van der Geest. 2019. (eds.). Nexus interventions for small tropical islands: case study Bonaire. WUR letter report 1900369.JAih. Wageningen, The Netherlands. 85 pp.

Dilrosun F. 2004. Inventory of the Fishery sector of St. Eustatius. Environmental department, pp. 14.

de Graaf, M., S. Piontek, D.C.M. Miller, T. Brunel, L.A.J. Nagelkerke (2015). Status and trends of St. Eustatius coral reef ecosystem and fisheries: 2015 report card. IMARES report C167/15. 43pp

Kitson-Walters, K. 2018. St Eustatius fisheries monitoring report 2017. Report from the Caribbean Netherlands Science Institute. 13pp

Sadusky, H., Chaibongsai, P., Die, D.J., et al. 2018. Management of moored fish aggregation devices (FADs) in the Caribbean. ICCAT Collect Vol Sci Papers 74:2230-2242.

Samples, K.C. and Sproul, J.T. 1985. Fish Aggregating Devices and open-access commercial fisheries: a theoretical inquiry. Bulletin of Marine Science 37(1): 305-317.

Stamatopoulos C. 2002. Sample-based fishery surveys: a technical handbook. FAO Fisheries Technical Paper. No. 425. Rome, FAO. Pp. 132.

Vermeij, M.J.A., Latijnhouwers, K.R.W., Dilrosun, F., Chamberland, V.F., Dubé, C.E., Van Buurt, G., Debrot, A.O. 2019. Historical changes (1905-present) in catch size and composition reflect altering fisheries practices on a small Caribbean island. PLoS 1. 


\section{Justification}

Report C031/20

Project Number: 4318100260

The scientific quality of this report has been peer reviewed by a colleague scientist and a member of the Management Team of Wageningen Marine Research

Approved: $\quad$ Esther Beukhof

Researcher

Signature:

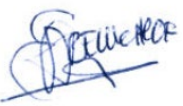

Date: $\quad 25-03-2020$

Approved: $\quad$ Drs. J. Asjes

Manager integration

Signature:

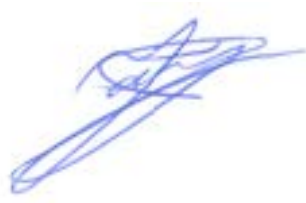

Date:

02-04-2020 


\section{Annex 1 : Logbook forms used in data collection}

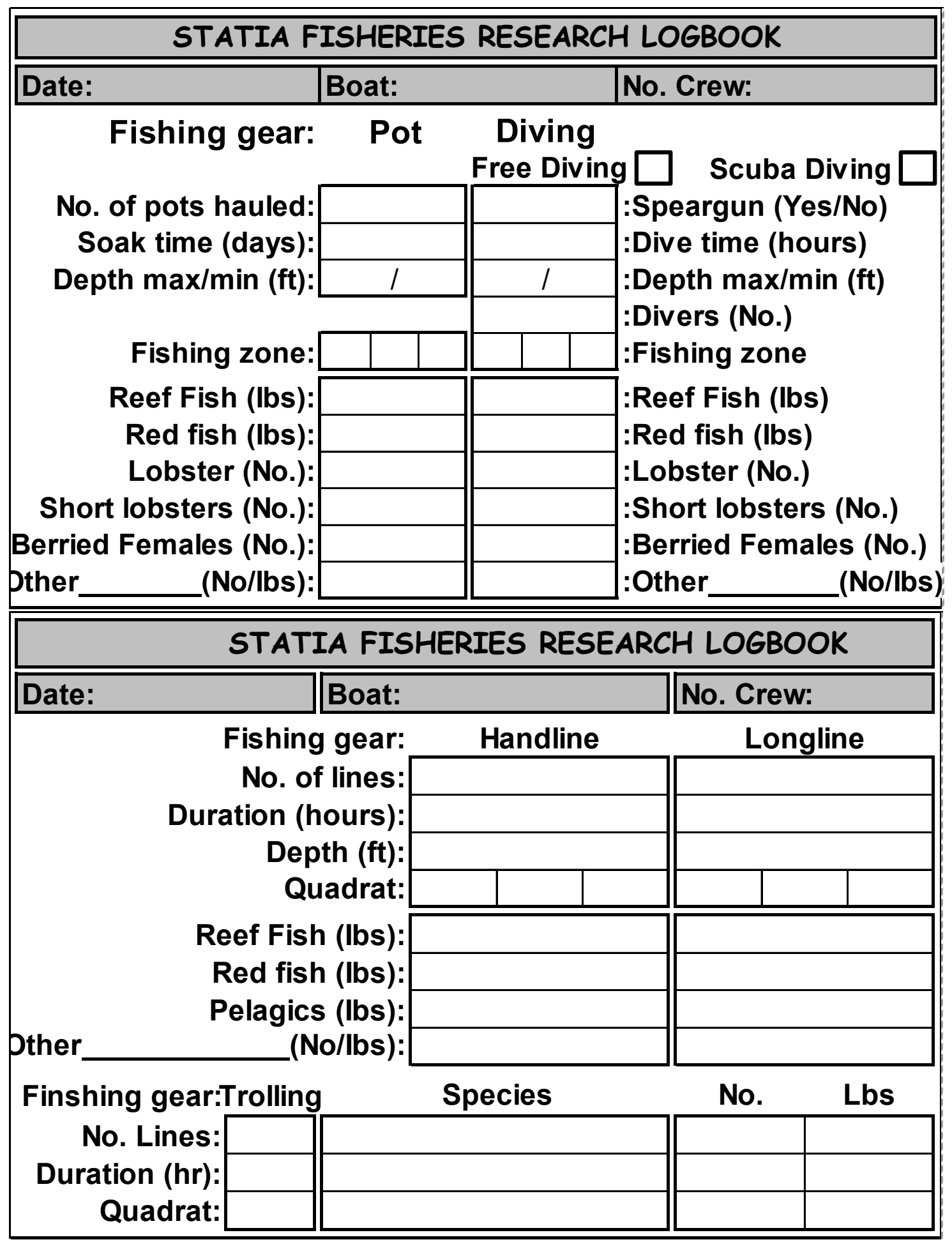


Annex 2 : monthly estimates of effort, catch rates and landings per métier per species category. 


\section{Lobster :}

Monthly variations num. trips fishing lobster
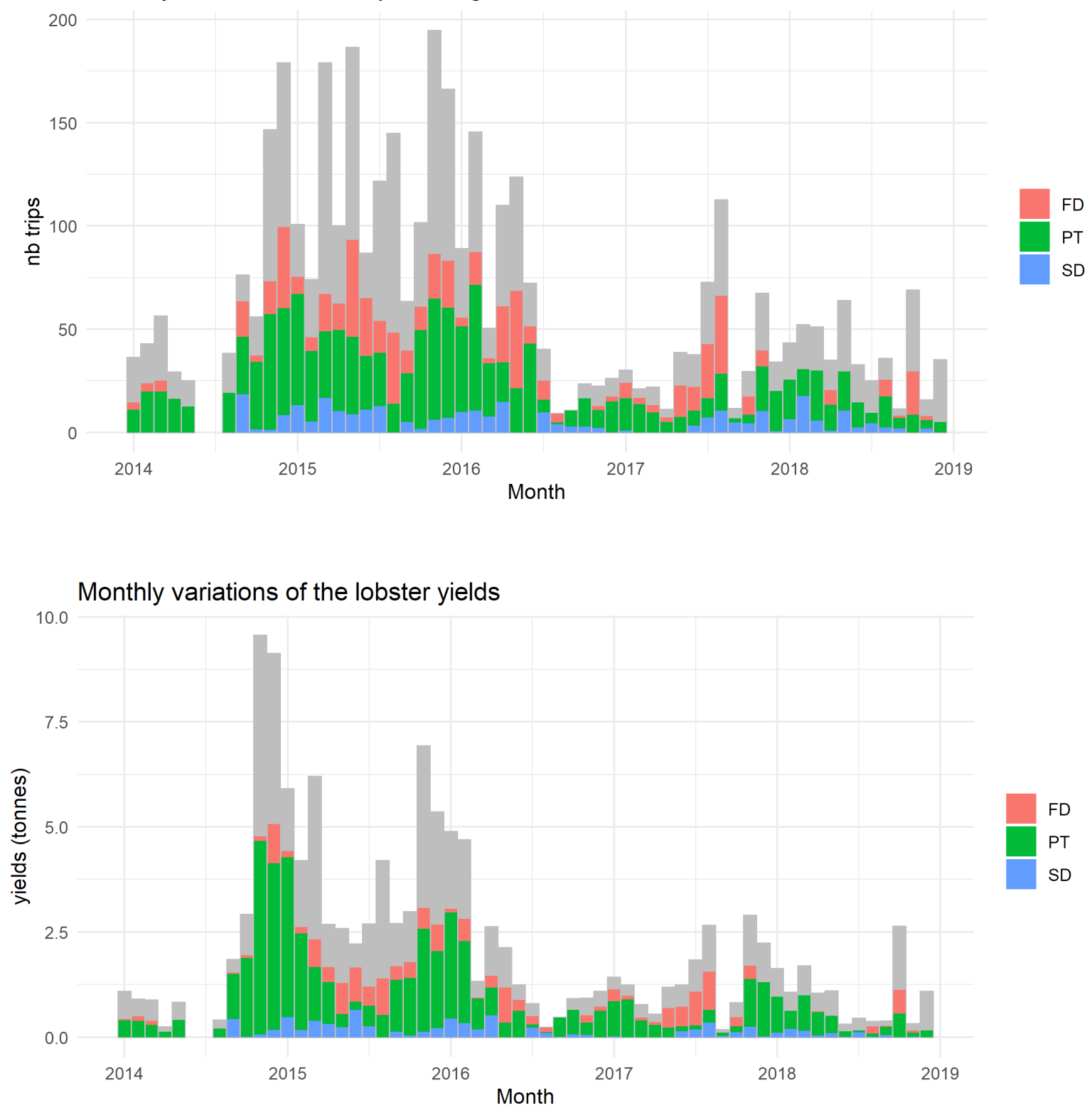

Monthly variations catch rates lobster

FD

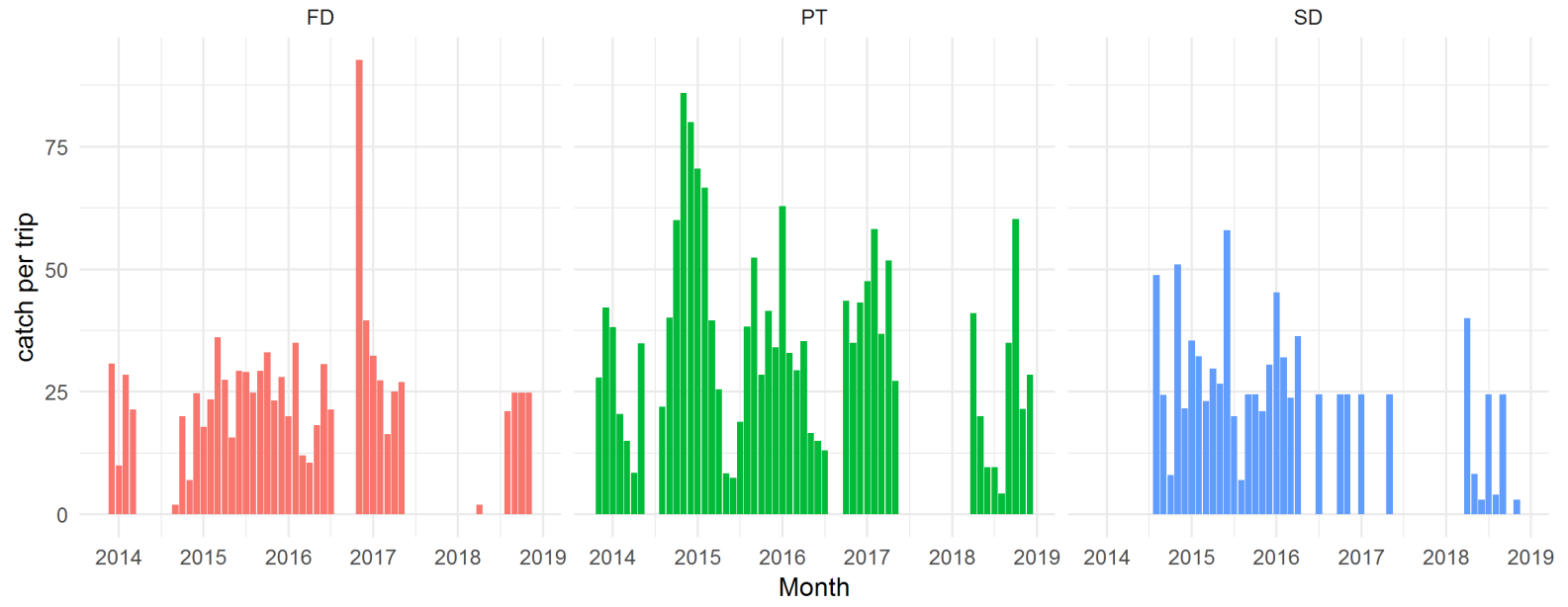




\section{Reef fish :}

Monthly variations num. trips fishing

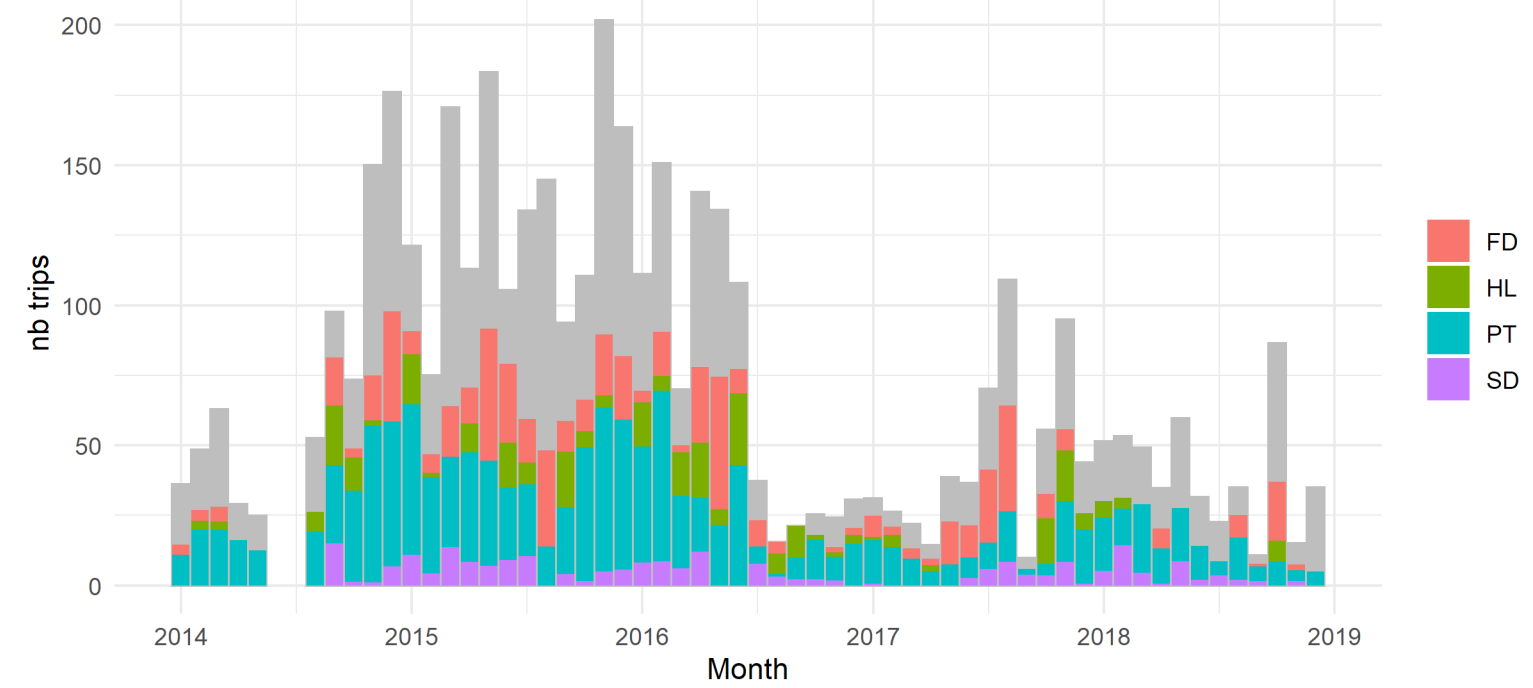

Monthly variations of the reef fish yields

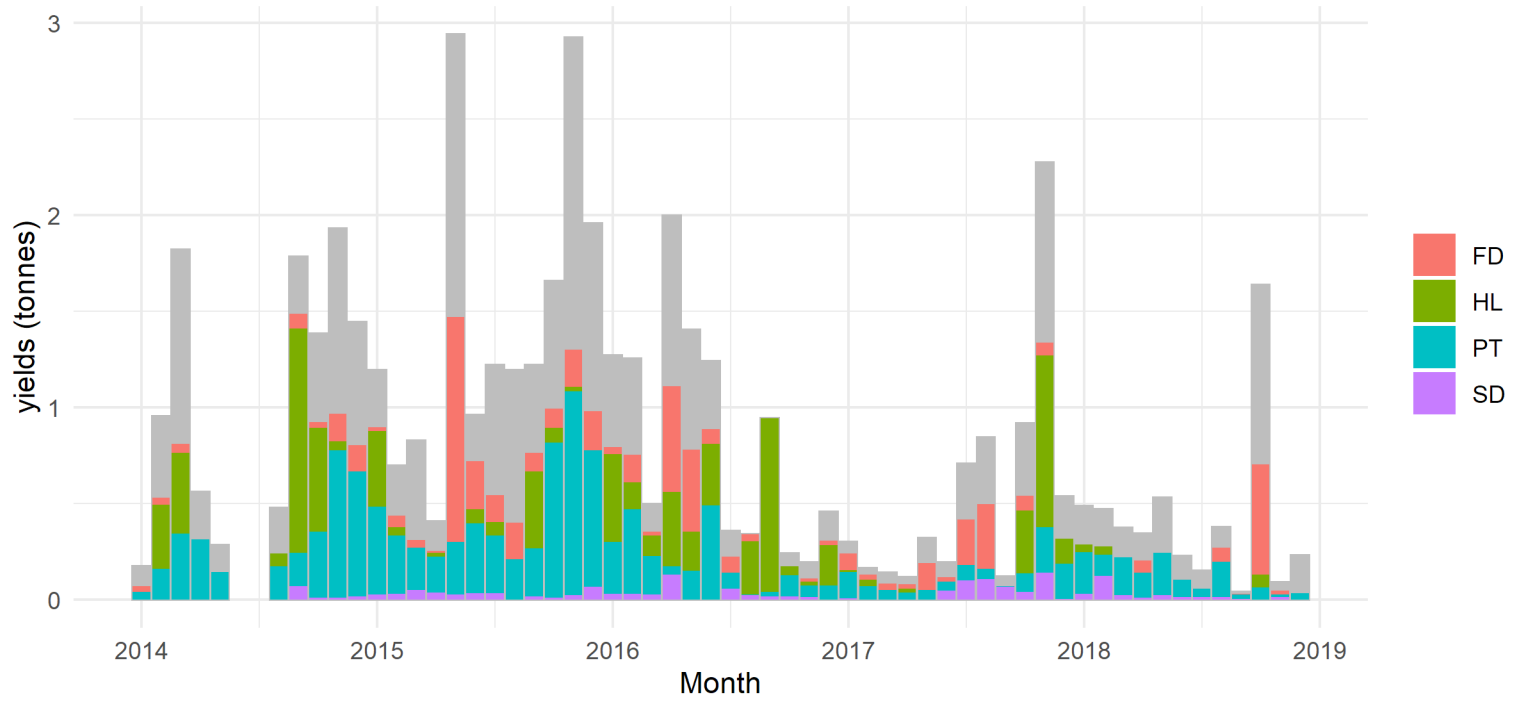

Monthly variations catch rates reef fish

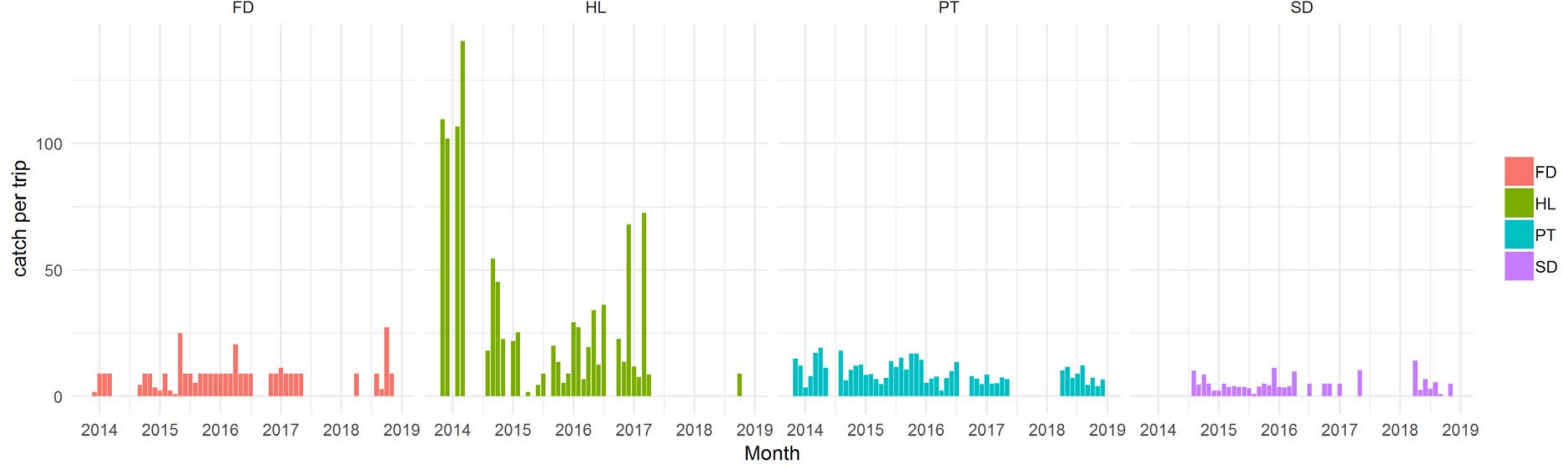




\section{Pelagic fish}

Monthly variations num. trips fishing pelagic fish

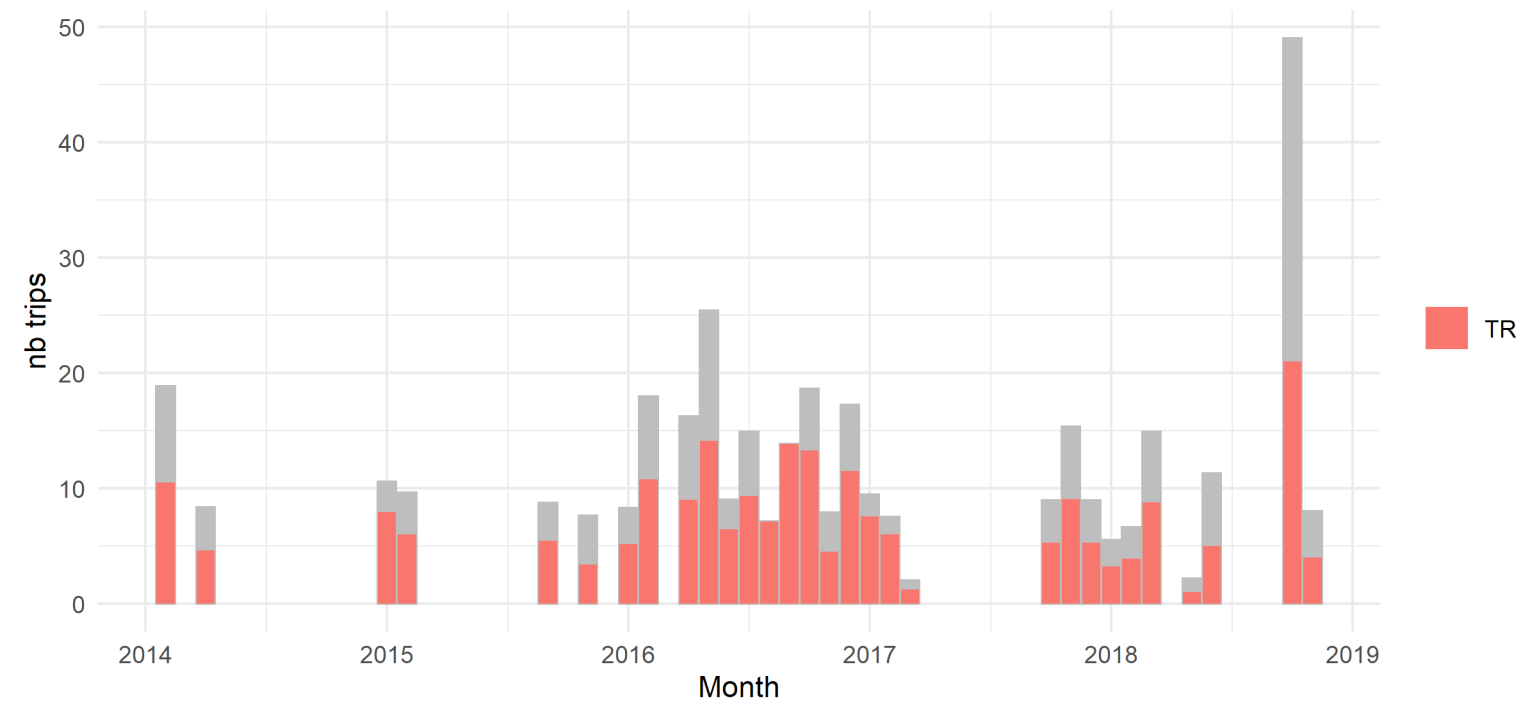

Monthly variations of the pelagic fish yields

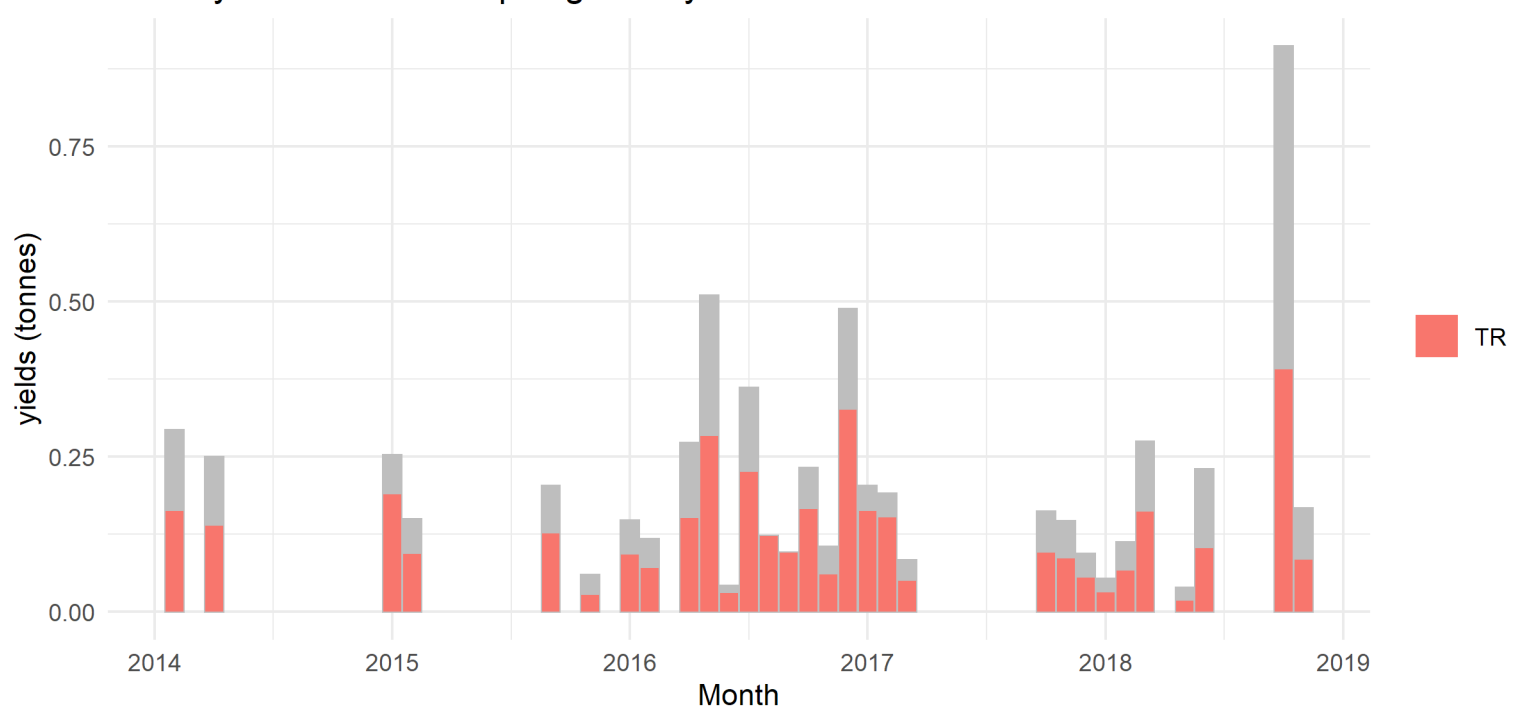

Monthly variations catch rates pelagic fish

TR

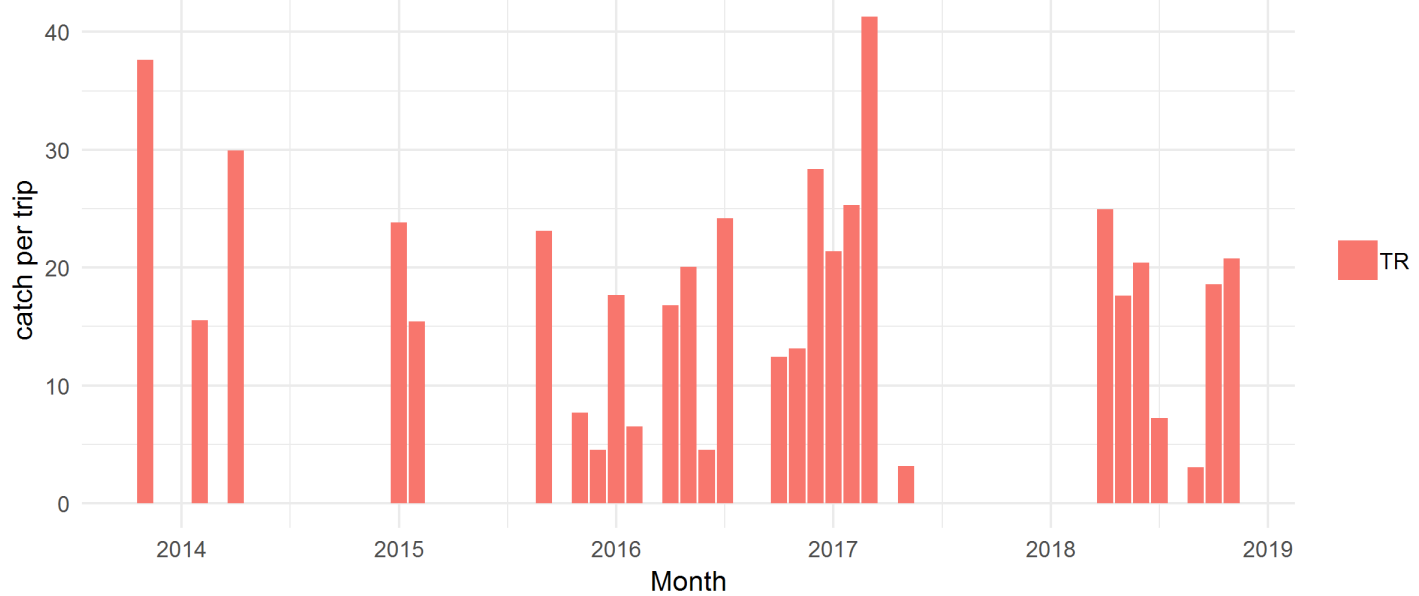




\section{Conch}

Monthly variations num. trips fishing

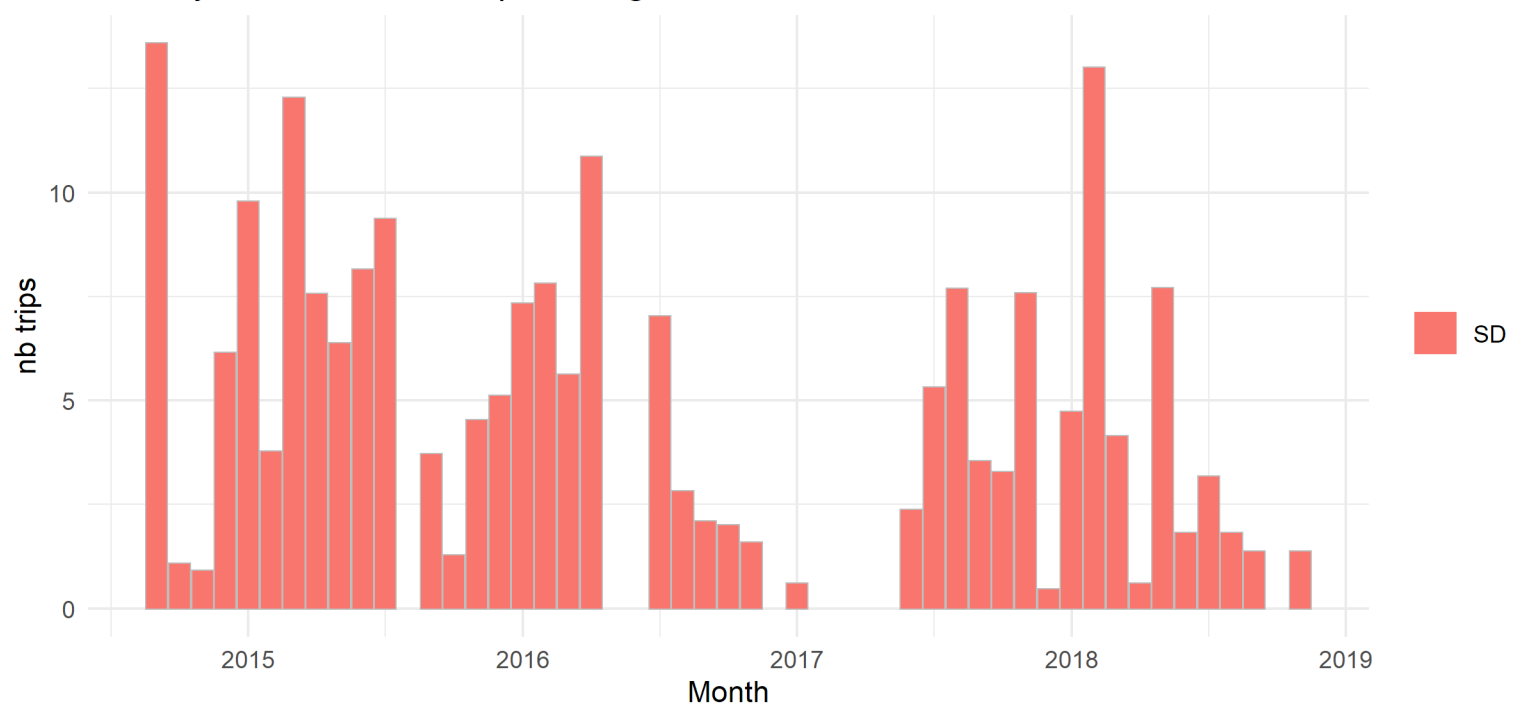

Monthly variations of the conch catches

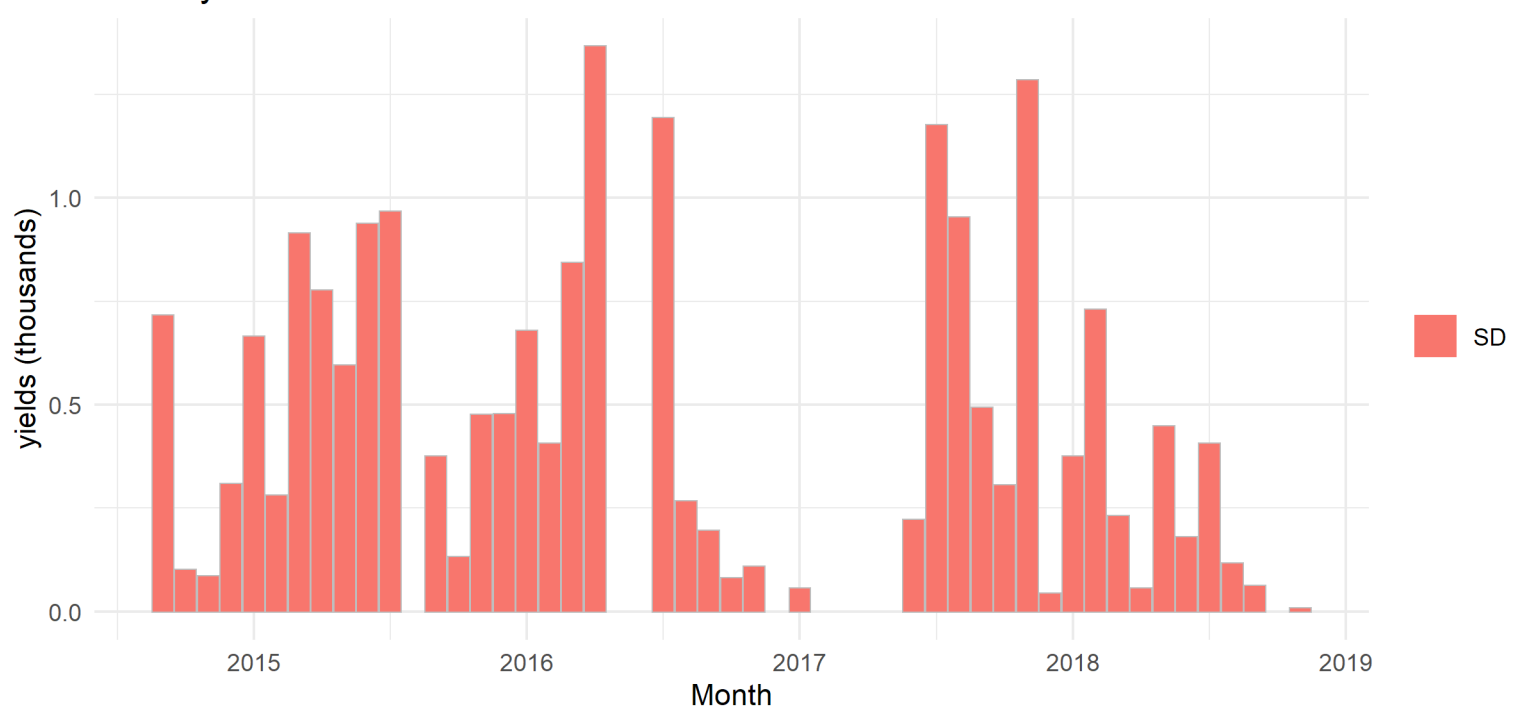

Monthly variations catch rates conchs

SD

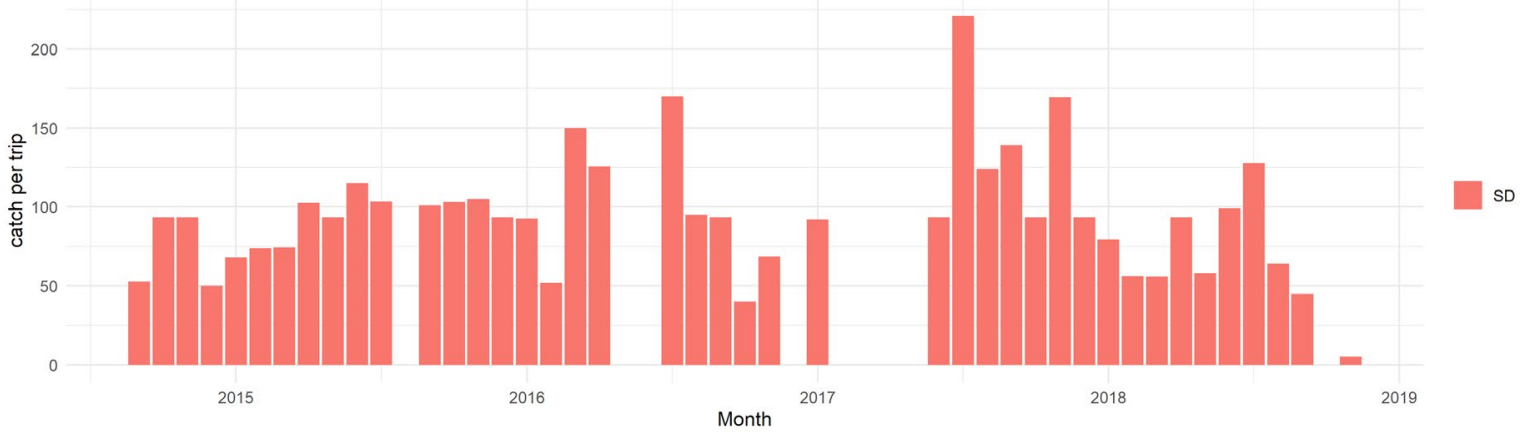




\section{Annex 3 : length frequency distribution of the reef fish landings in fish traps}

The following plots show the length distribution of the landings per species and per year, with the mean length shown as a vertical line. 


\section{Length distribution blue tang}

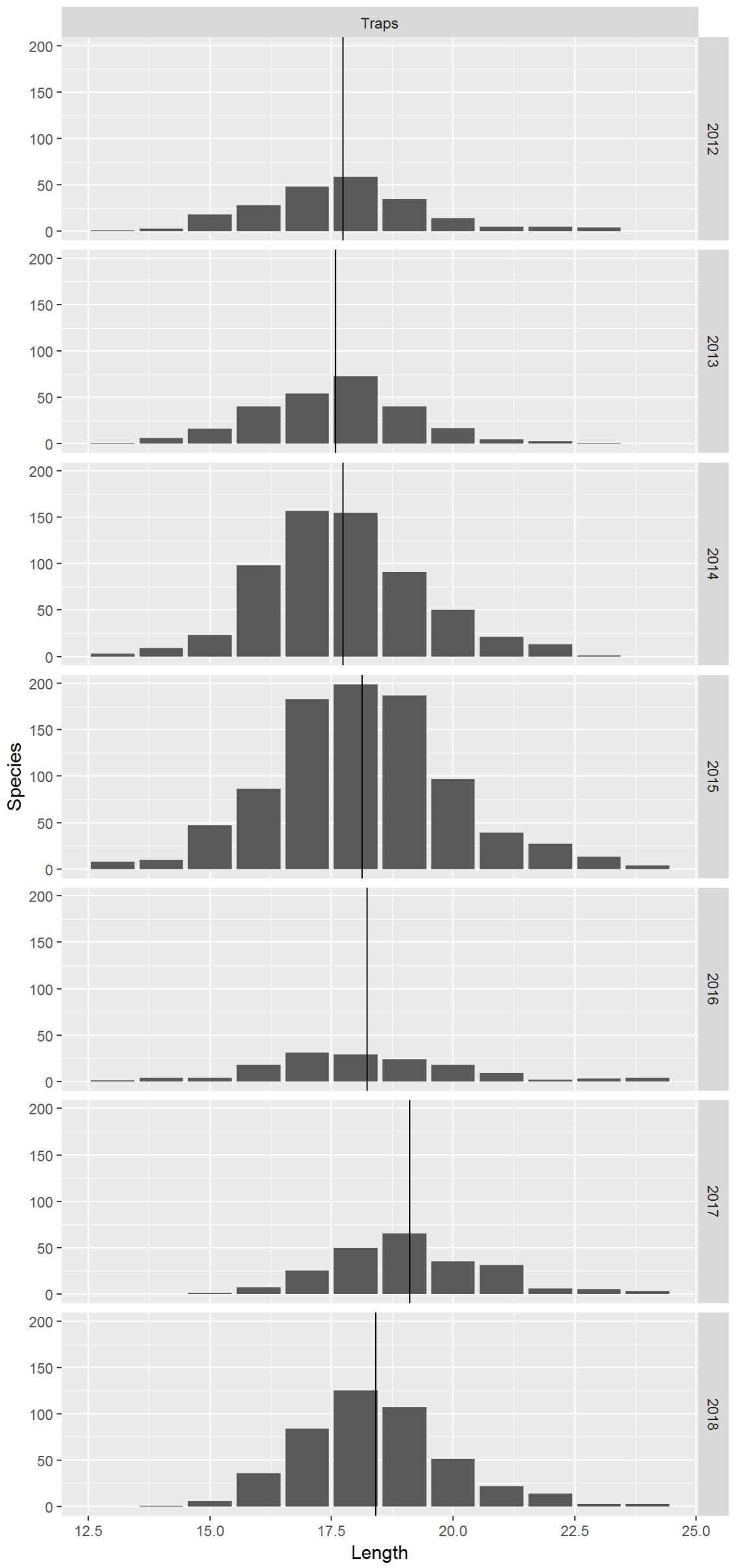


Length distribution coney

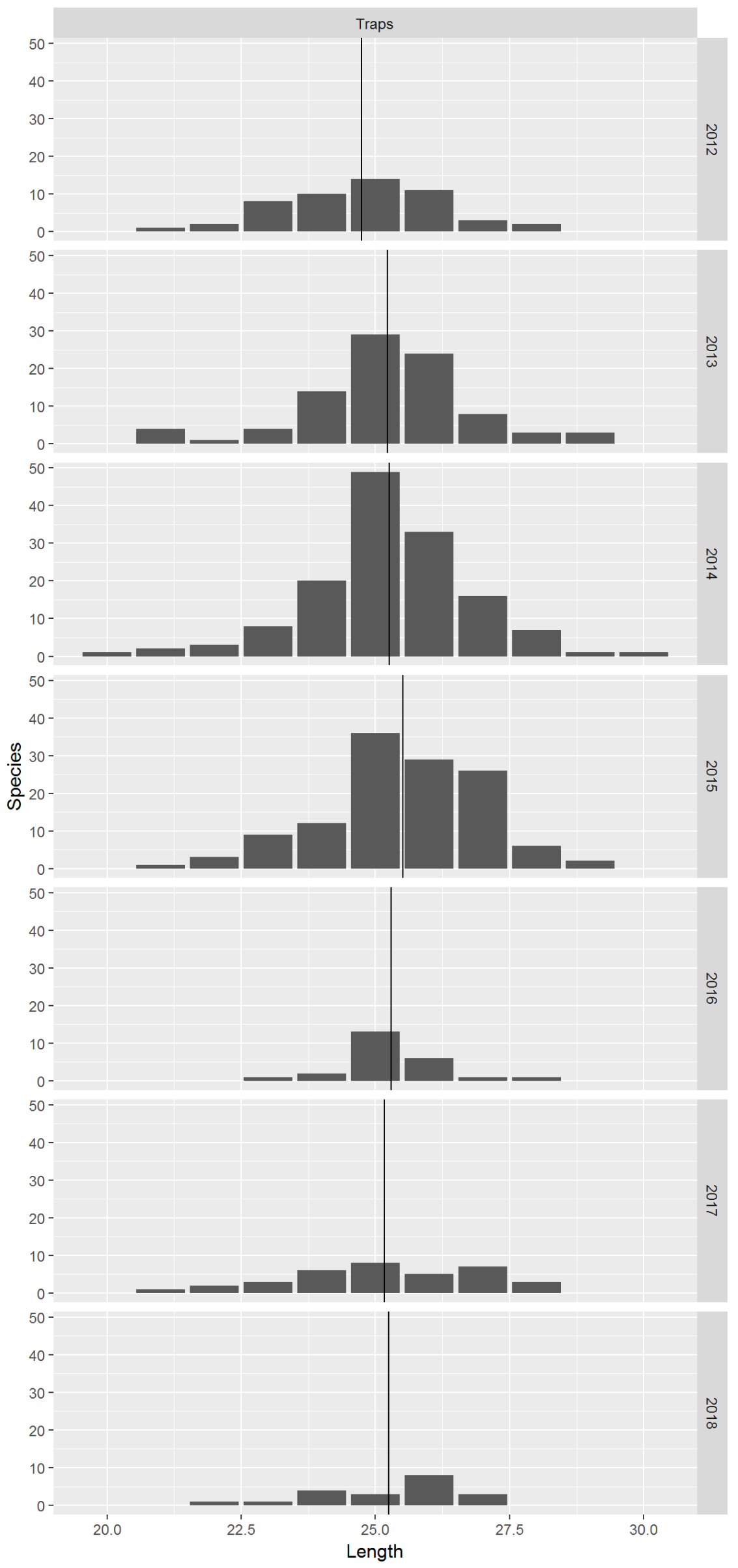


Length distribution doctorfish
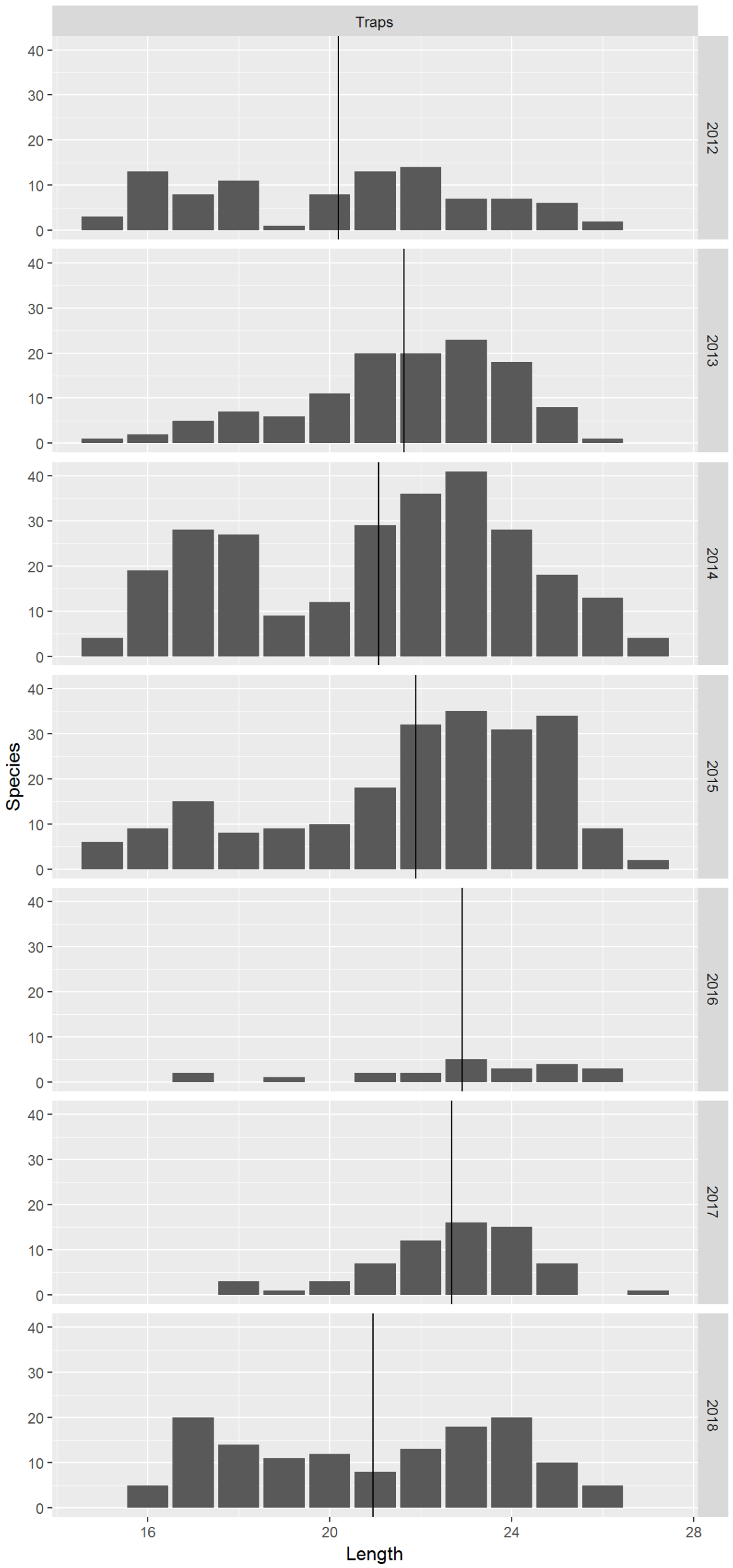


\section{Length distribution honeycomb cowfish}

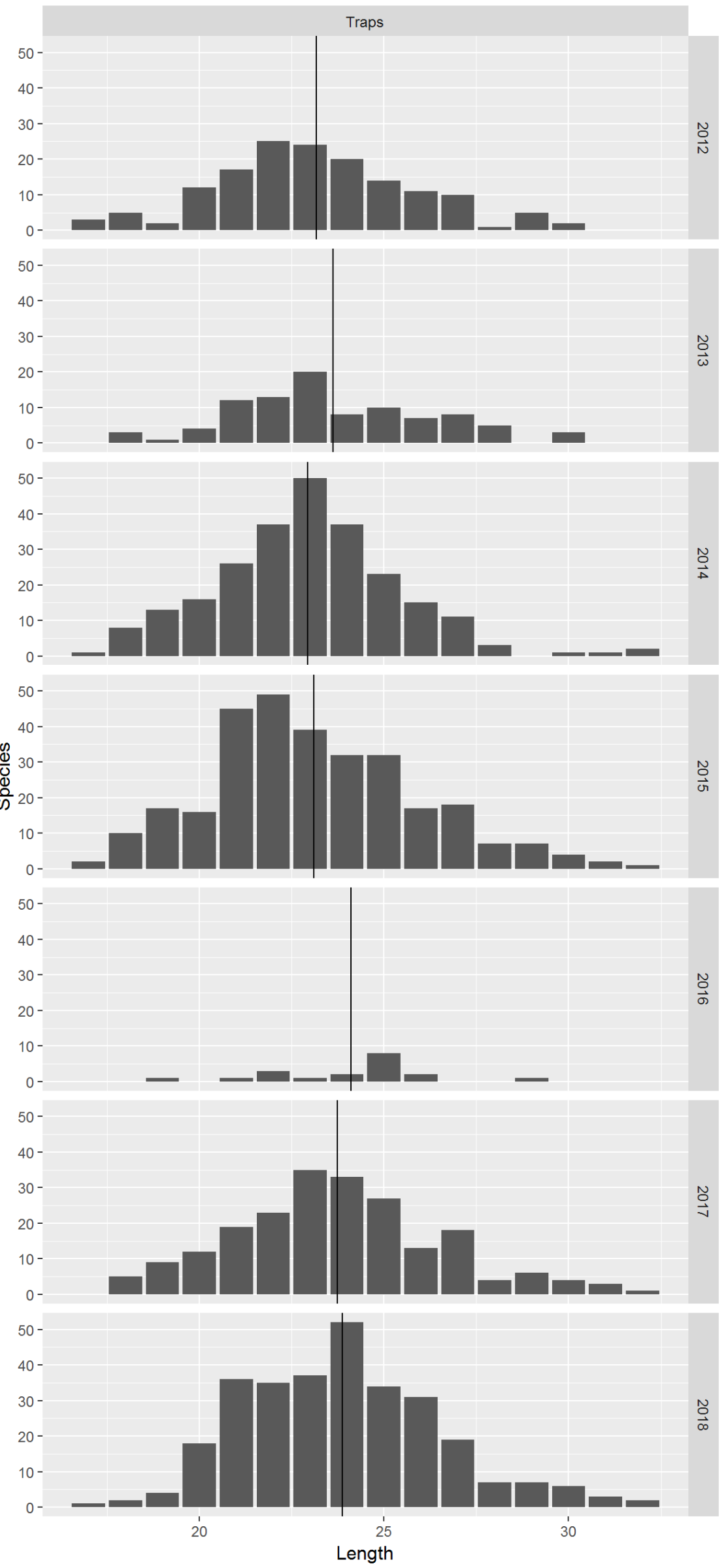


Length distribution ocean surgeon

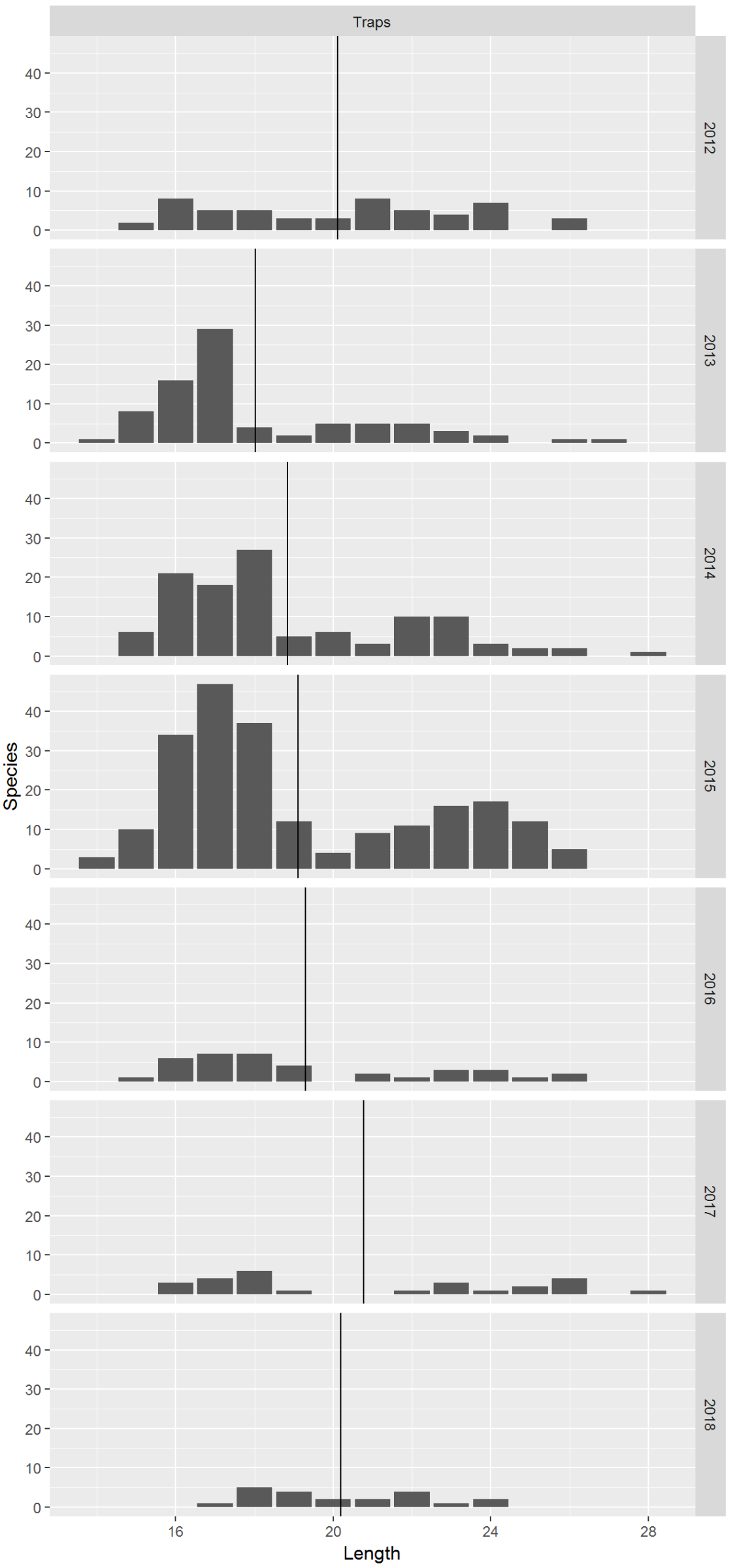




\section{Length distribution queen triggerfish}

Traps

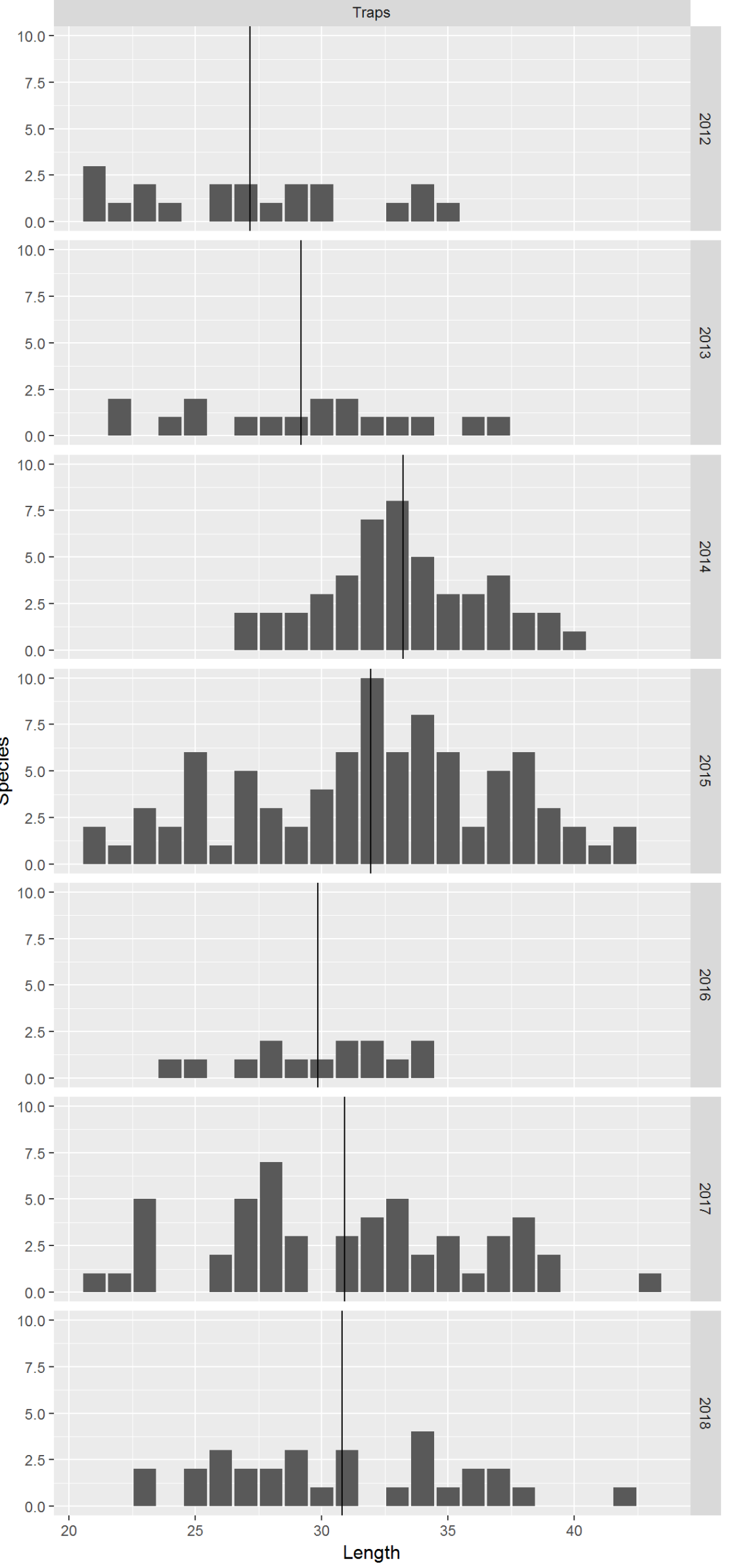




\section{Length distribution red hind}
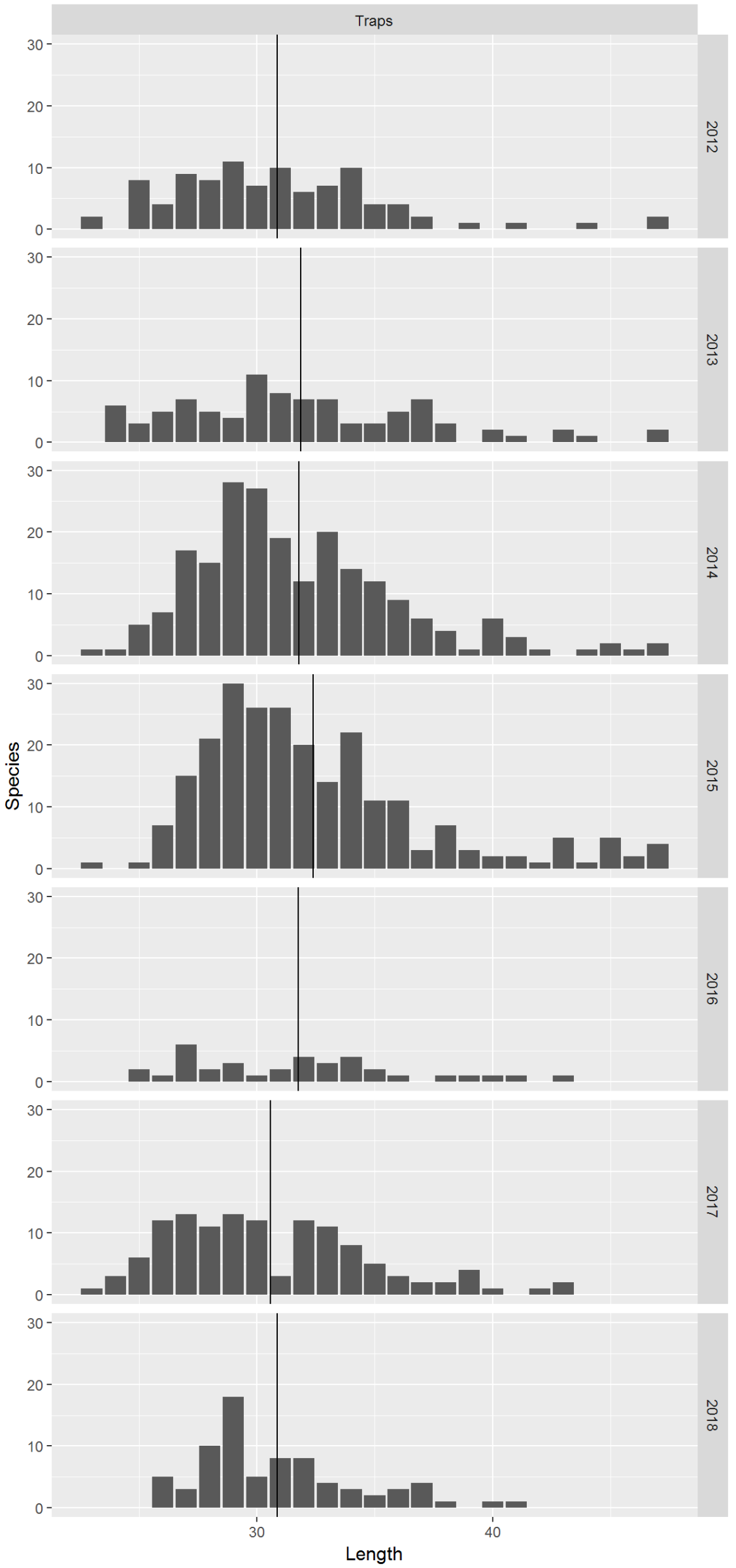
Length distribution squirrelfish
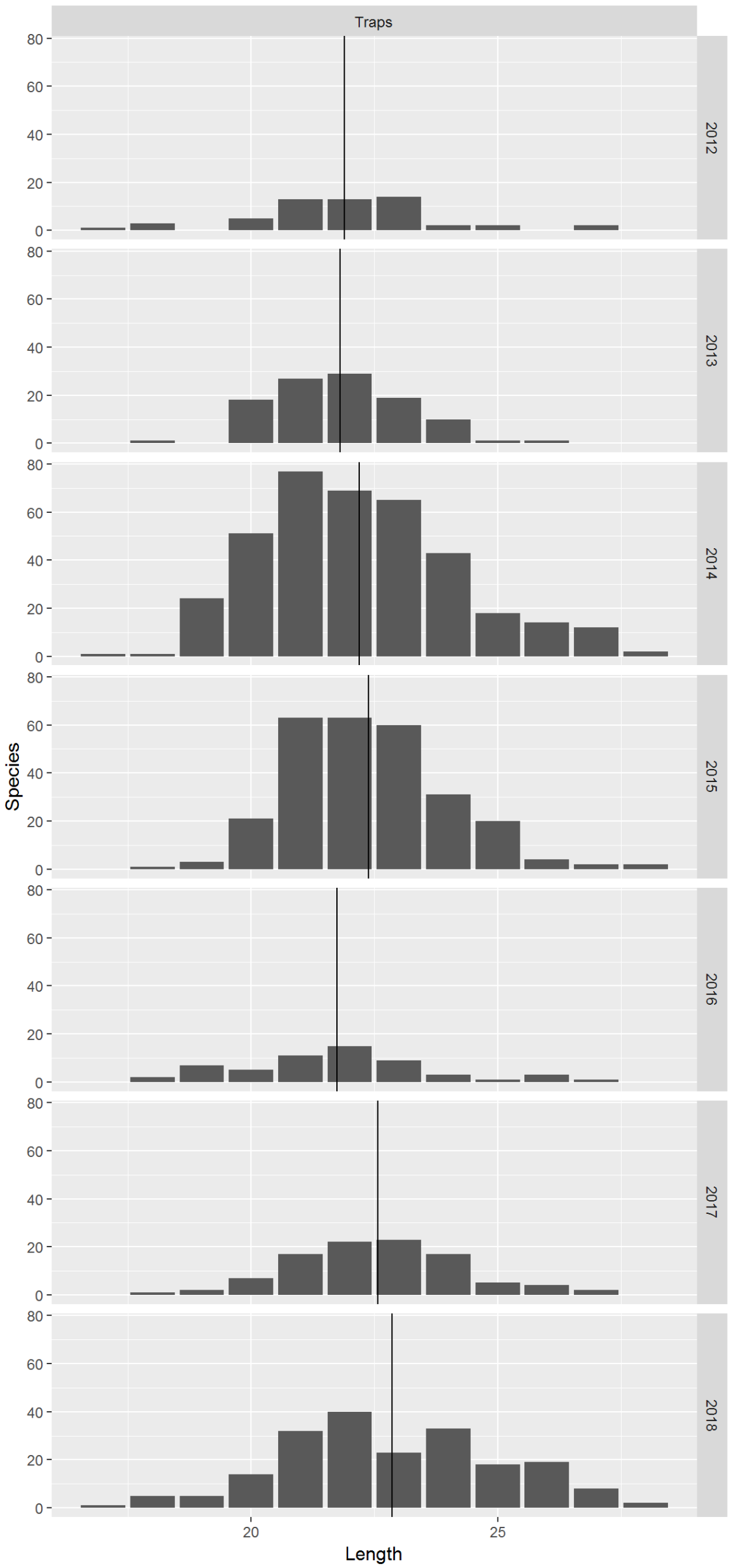
Length distribution stoplight parrotfish

Traps

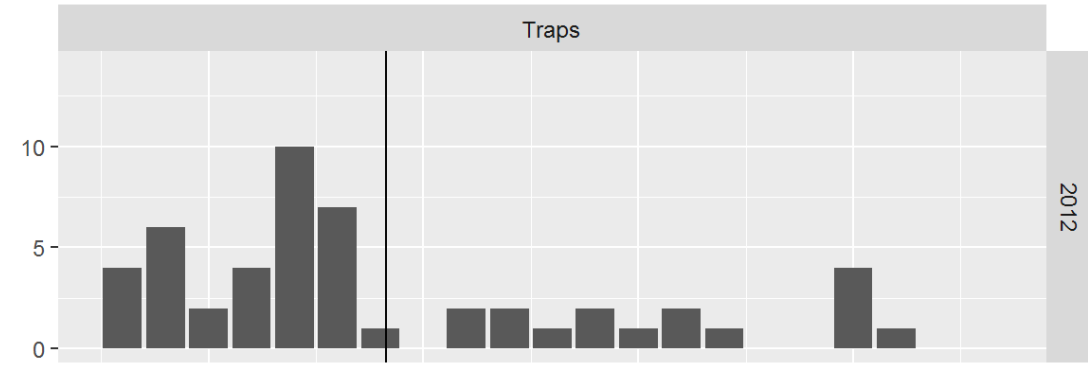

$\stackrel{N}{N}$
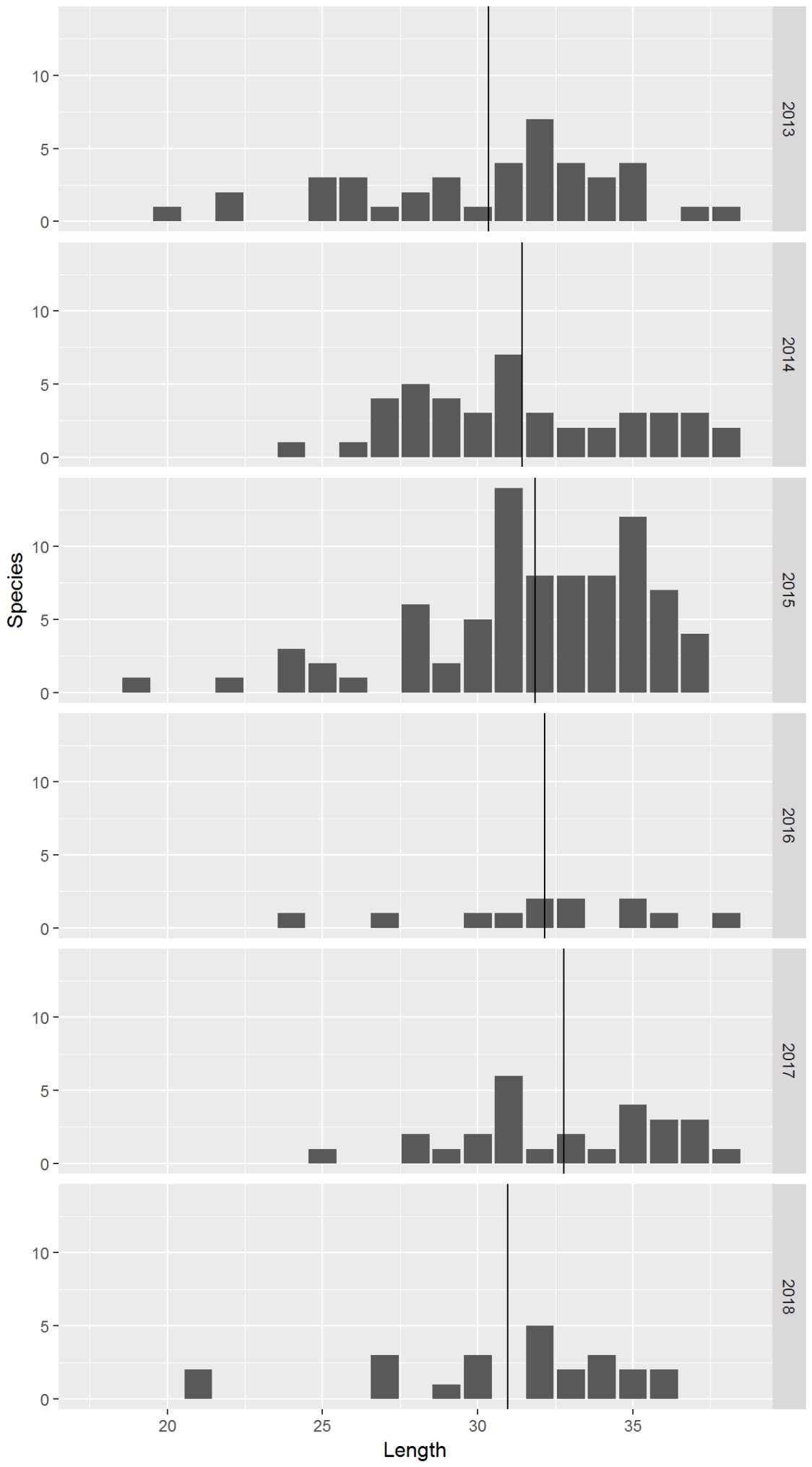
Length distribution white spotted filefish

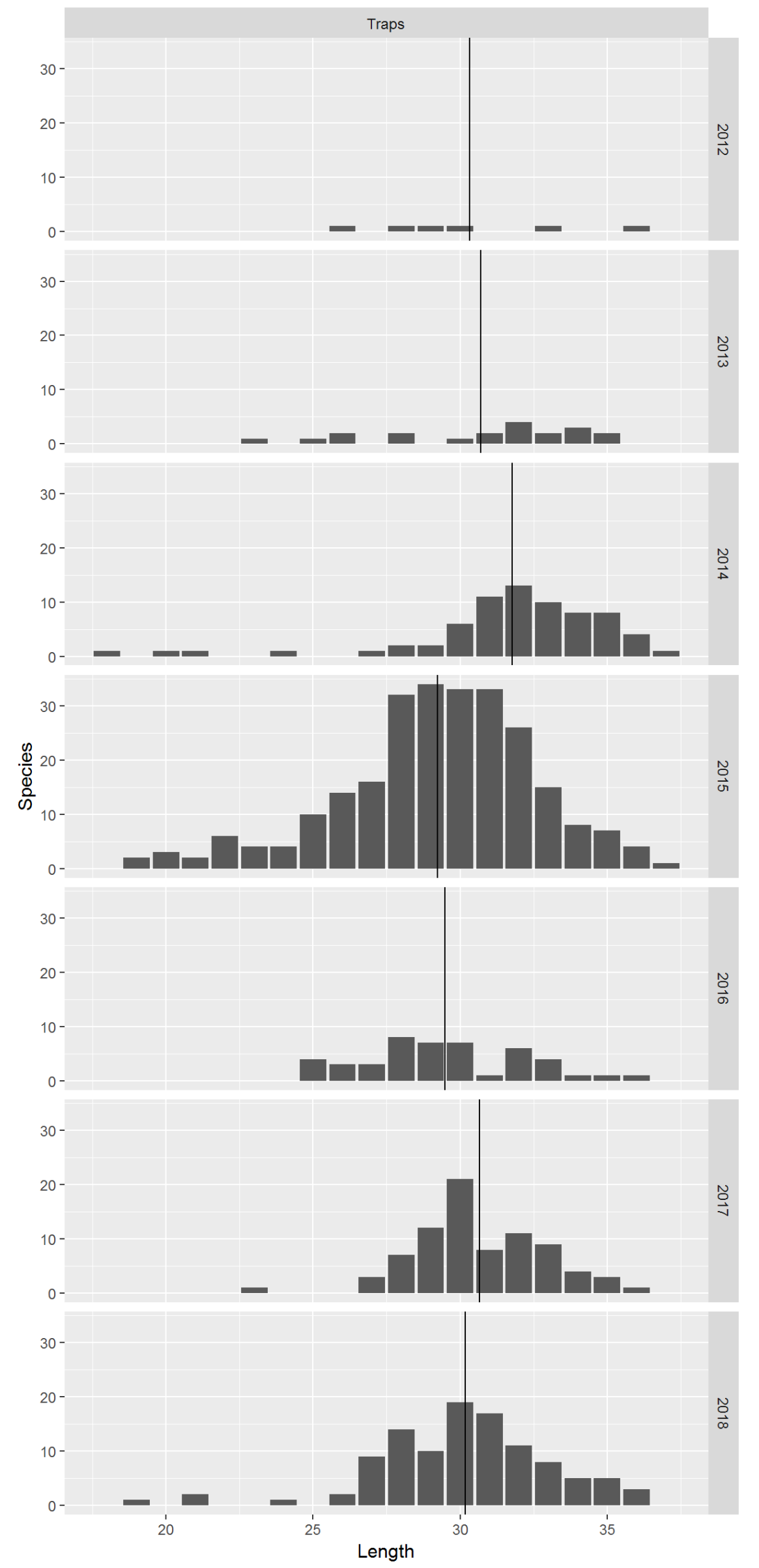




\section{Length distribution yellow goat fish}

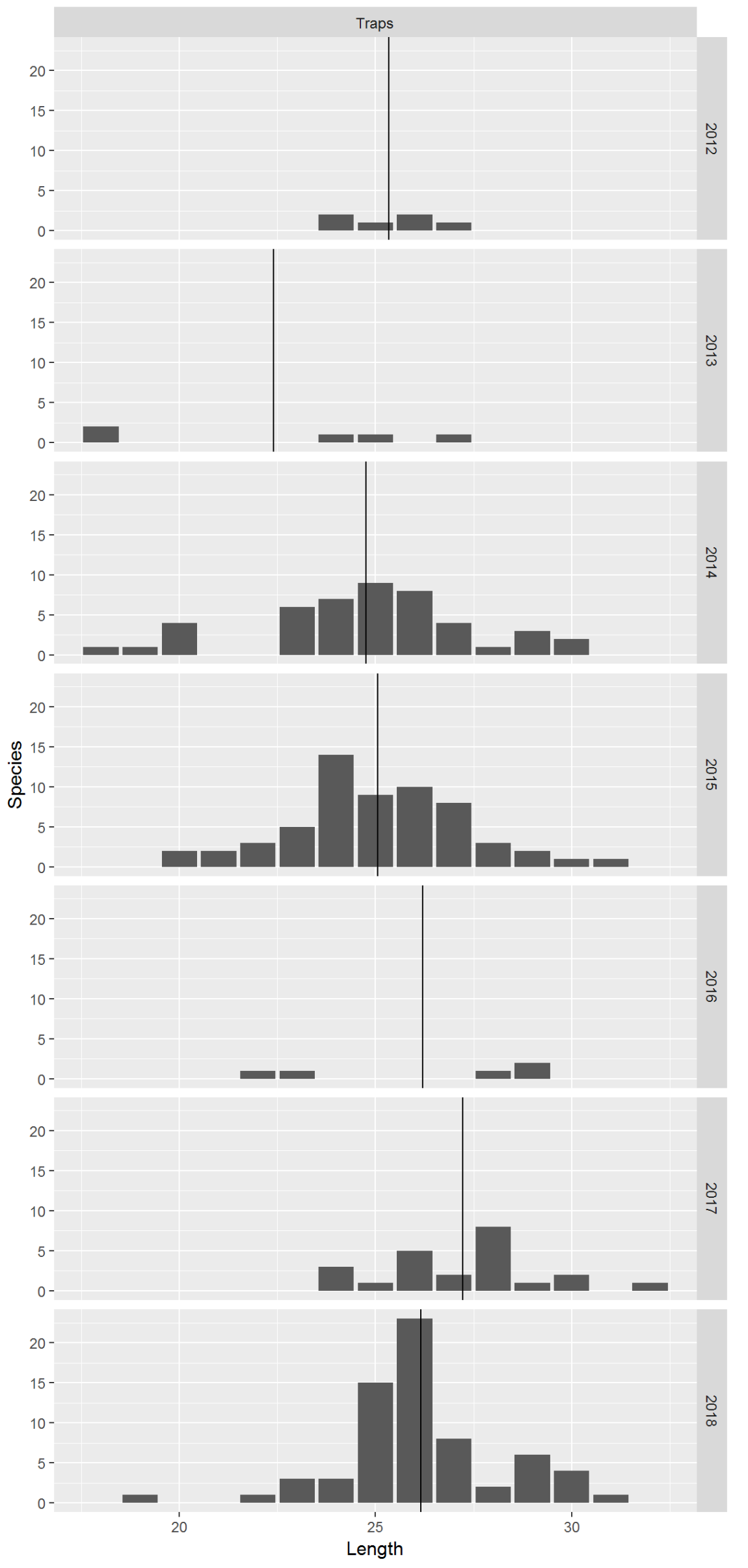

Wageningen Marine Research report C031/20 | 49 of 51 


\section{Length distribution yellowtail snapper}

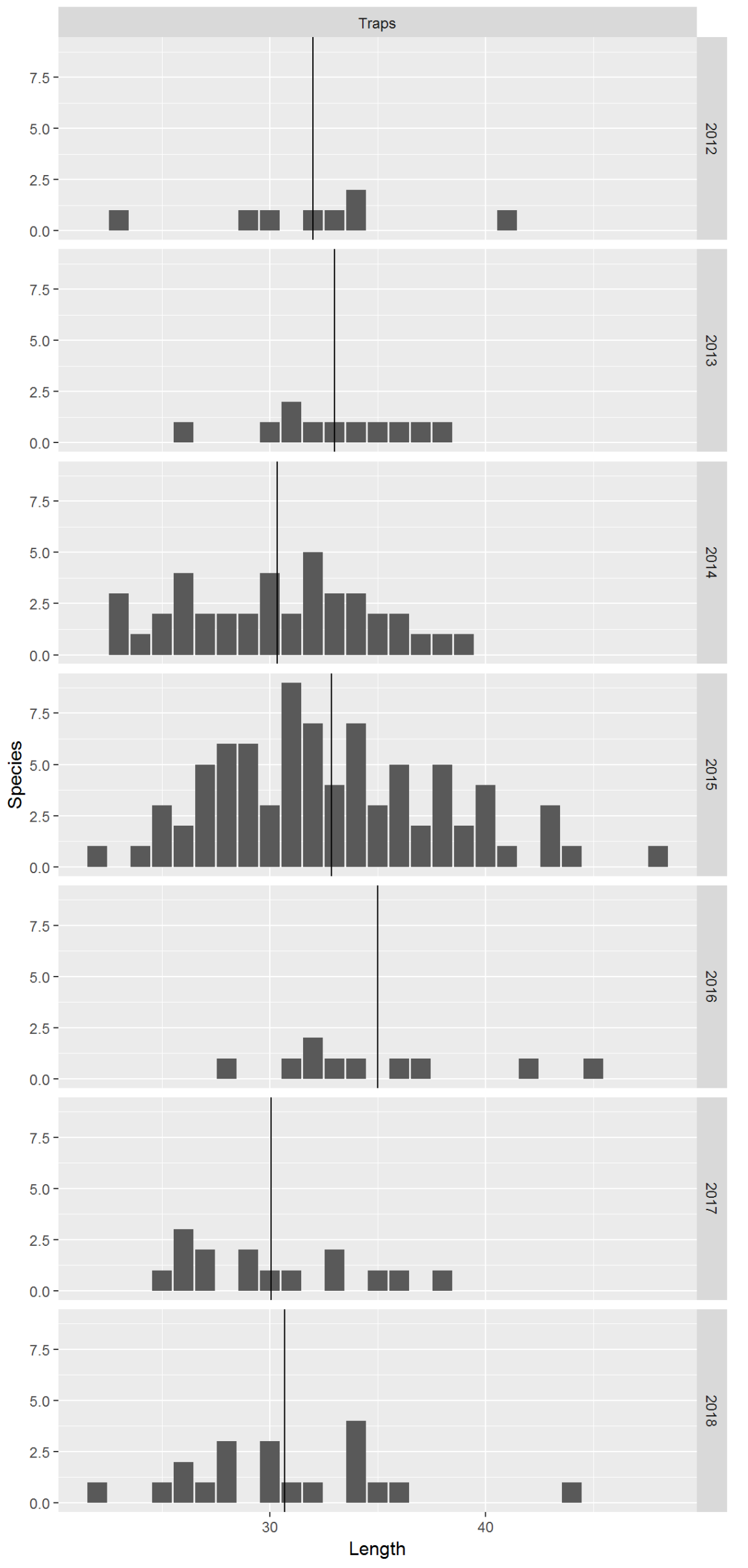


Wageningen Marine Research

T +31(0)317480900

E: marine-research@wur.nl

www.wur.eu/marine-research

Visitors' address

- Ankerpark 271781 AG Den Helder

- Korringaweg 7, 4401 NT Yerseke

- Haringkade 1, 1976 CP IJmuiden
With knowledge, independent scientific research and advice, Wageningen Marine Research substantially contributes to more sustainable and more careful management, use and protection of natural riches in marine, coastal and freshwater areas.

Wageningen Marine Research is part of Wageningen University \& Research. Wageningen University \& Research is the collaboration between Wageningen University and the Wageningen Research Foundation and its mission is: 'To explore the potential for improving the quality of life' 